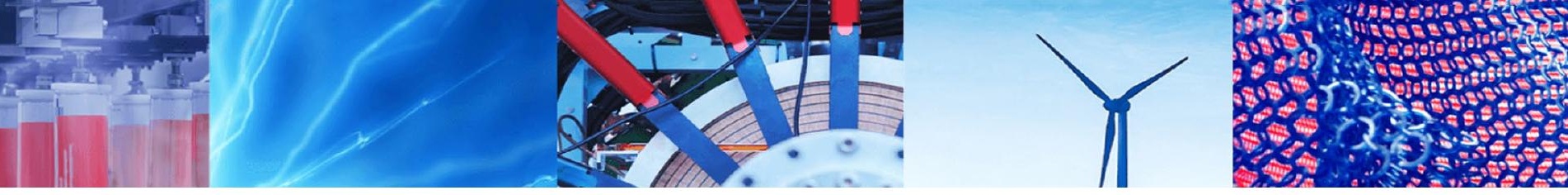

Review Paper

\title{
Applications of polyimide coatings: a review
}

\author{
Ayse Sezer Hicyilmaz ${ }^{1}$. Ayse Celik Bedeloglu ${ }^{1}$ (i)
}

Received: 25 July 2020 / Accepted: 10 February 2021 / Published online: 23 February 2021

(c) The Author(s) $2021 \quad$ OPEN

\begin{abstract}
Polyimides, high-performance polymers with superior properties such as high temperature stability, resistance to solvents and high strength, can be used in high-tech applications of the aerospace and aviation, medical or electronics industry in different forms (film, fiber, nanofiber, membrane, foam, adhesive or coating). Among these applications, coating has a special place and is used to develop advanced structures having high temperature resistance, flame retardancy and etc. for high tech industries via an economical and feasible way. Therefore, in this review, we aimed to report the broad application status of polyimide coatings by reviewing publications, patents and commercial products. Thus, this study can assist in selecting suitable polyimide types and production methods for polyimide coating applications and in understanding their applicability for future products.
\end{abstract}

Keywords Polyimide · Poly (amic acid) · Coating · Optical fiber · High temperature resistant · Electrical insulation · Anticorrosion

\section{Introduction}

Polyimide (PI) is a high performance polymer that has superior properties such as temperature stability, resistance to solvents and mechanical strength. Due to their superior properties, Pls are used in different forms such as film, fiber, nanofiber, membrane, foam, adhesive or coating in high technology applications such as aerospace industry, medical and electronic devices, sensors [1-3]. PI films are used as thermal control coatings and also a protective layer for electronic devices and space applications thanks to remarkable optical properties (transparency and low solar absorption and infrared emission), high thermal stability and wide service temperature $\left(-300-+300^{\circ} \mathrm{C}\right)$, radiation resistance, enhanced electrical insulation (dielectric constant 3.4- 3.5), low density, toughness, flexibility, and high mechanical stability [4-11].

PI thin films are preferable for coating applications due to adhesion and transparency properties [12]. Especially coating applications are important because this is an economical way to obtain functional material, since the cost of the material decreases by using low amount of polymer. On the other hand, it is possible to provide high-value added material by an easy and economical process.

In the literature, there are numerous studies about different forms of PIs [13]. PI coating applications have attracted attention by researchers and manufacturers from past to present. Although there have been many reviews about PI chemistry [1,14-19] or applications of PI materials [4, 20-24], no studies focusing on coating applications of PIs have been found. Readers can easily find information on PI coatings in this review and the cited sources. In this paper, by reviewing the studies in the literature on PI coatings and the patents reported on commercial products, the properties of the polyimides are explained in the first part, then the coating methods are explained and the application areas are given in detail in the last section.

Ayse Celik Bedeloglu, ayse.bedeloglu@btu.edu.tr| ${ }^{1}$ Department of Polymer Materials Engineering, Bursa Technical University, Mimar Sinan Campus, Yildirim, 16310 Bursa, Turkey. 


\section{Properties of polyimides}

High temperature resistance, mechanical and chemical stability, high glass-transition temperature ( $\mathrm{Tg})$, optical transmittance, low dielectric constant properties are characteristic for PI materials [18]. All of the mentioned properties of PIs can vary depending on chemical structure and macromolecular conditions such as molecular weight (MW), crystallinity or intermolecular forces [1, 25].

Thermal resistance is one of the most important property of the PIs. Highly rigid aromatic units provide thermal resistance to the polymer due to high $\mathrm{Tg}\left(>300^{\circ} \mathrm{C}\right)$ and decomposition temperature $\left(500-600{ }^{\circ} \mathrm{C}\right)[8,15$, $26,27]$. Thermal oxidation resistance and high limiting oxygen index (LOI: 37-45) value of PIs originated from already oxidized structure of imide and ether linkages, moreover, increasing MW increases the oxidation resistance of polymers $[1,8]$. Besides, PIs have high char amount (appr. 60\%) and low heat conductivity (0.12 W/m.K) [26].

Besides rigid aromatic structure, dipole-dipole interactions between carbonyl bonds in the imide structure of macromolecules and charge transfer increases the $\mathrm{Tg}$, mechanical and chemical stability of PIs. Amorphous morphology, flexible linkages in the macromolecule (such as ether) gives the elongation property to the PIs [1]. Highly aromatic structure and strong intermolecular interactions result low solubility and non-melting structure [16]. Adhesion of PIs on different substrates have been attributed to polar and non-polar functional groups in the structure $[12,13,28,29]$. Since the synthesis of new types of PIs (low-melt PI, soluble PI, thermoplastic $\mathrm{PI}$, colorless $\mathrm{PI}$ etc.) and the development of new coating methods, disadvantages of Pls are overcome by the researchers, the application area of PI coatings is expanding day by day.

First aromatic PI was synthesized by Marston Bogert in 1908 [30].Then at 1965, first commercial PI film was produced by DuPont named as Kapton [13]. Generally, aromatic $\mathrm{Pl}$ is produced by two step method: First step is polyamic acid (PAA) synthesis from dianhydride and diamine monomers through exothermic polycondensation reaction in a dipolar solvent $(\mathrm{N}, \mathrm{N}$ dimethyl acetamide (DMAC), N, N dimethyl formamide (DMF), $\mathrm{N}$-methylpyrollidone (NMP) etc.) and second step is imidization reaction which is applied after solvent elimination from PAA as seen in Fig. 1. [18, 31, 32]. Commonly used dianhydrides are pyromellitic dianhydride (PMDA), benzophenone-3,3',4,4'-tetracarboxylic dianhydride (BTDA) and 1,2,4,5-benzenetetracarboxylic dianhydride due to their high electron affinities $\left(E_{a, \text { PMDA }}=1.90 \mathrm{eV}\right.$,
$E_{a, B T D A}=1.55 \mathrm{eV}$. On the other hand, phenylene diamine and 4,4'-oxydianiline (ODA) structures with high basicity $(p K a=6.08)$ are preferred because of their high reactivity. Since PAA was synthesized with an equilibrium reaction, purity of the monomers is crucial to obtain high molecular weight PAA. Besides, while PAA forms amorphous random coils, rigid rod-like chain structures can be obtained with poly (amic ester) synthesized with diester diacid chloride and diamine. By mixing these two polymers, a polyimide fiber with high mechanical strength (462 $\mathrm{MPa})$ and modulus (125 GPa) can be obtained. Moreover, it is possible to increase the solubility of polyimide precursor polymer in the non-polar solvents by synthesizing poly (amic silylester) with $\mathrm{N}, \mathrm{N}^{\prime}$-bis(trialkylsilyl)diamines and aromatic dianhydrides at room temperature. During imidization reaction; while the ring closure reaction of the amic acid structures between $150{ }^{\circ} \mathrm{C}-400{ }^{\circ} \mathrm{C}$, proceeds, the solubility and the $\mathrm{Tg}$ of polyimide increases $[18,31]$. Two types of imidization treatment are applied as thermal and chemical imidization reactions. Gradual heating from $150{ }^{\circ} \mathrm{C}$ to $400{ }^{\circ} \mathrm{C}$ for a certain time is necessary to complete thermal imidization reaction [1, 13, 31, 33].

Chemical imidization is obtained by cyclodihydration reaction of PAA with acid anhydrides in dipolar aprotic solvents or tertiary diamine catalysts. In addition to the twostage production method, there are many polymerization methods [13] for producing Pls such as;

1. One step method (solution polymerization and melt polymerization).

2. Diesters of tetracarboxylic acids (polyetherimide synthesis, PMR-15.)

3. Polyisoimides (lower Tg, more soluble and lower melt viscosity).

4. Ester derivatives of poly (amic acids) (storage stability, solubility).

5. Nucleophilic substitution reaction (poly (ether imides), lower Tg $\left(200-280^{\circ} \mathrm{C}\right)$, injection moldable, ULTEM 100 Thermoplastic Resin).

6. Exchange reaction (imidization without water molecule elimination).

7. Polymerization of dianhydrides and diisocyanates.

8. Cycloaddition reaction (Diels-Alders reaction of bismaleimides).

9. $\mathrm{C}-\mathrm{C}$ coupling reaction.

In today's world where science and technology are rapidly developing, focusing on all the important features of polyimide instead of its limited characteristic properties can open up new perspectives and enable the development of new products. In this scope, polyamideimides and fluorinated PIs are other types of PIs that are developed to obtain the required properties for advanced. Commonly 
<smiles>O=c1oc(=O)c2cc3c(=O)oc(=O)c3cc12</smiles>

PMDA<smiles>Nc1ccc(Oc2ccc(N)cc2)cc1</smiles>

ODA<smiles>CC(C)(C)NC(=O)c1cc(C(=O)Nc2ccc(Oc3ccc(C(C)(C)C)cc3)cc2)c(C(=O)O)cc1C(=O)O</smiles>

Polyamic Acid<smiles>CC(C)(C)c1ccc(Oc2ccc(-n3c(=O)c4cc5c(=O)n(C(C)(C)C)c(=O)c5cc4c3=O)cc2)cc1</smiles>

Polyimide

Fig. 1 Synthesis mechanism of Kapton [32]

used polyamideimide is thermoplastic PIs with enhanced mechanical strength, thermal and oxidative stability. Fluorinated Pls are developed for optoelectronics and solar cells requiring transparency or controllable light transmittance $[13,34,35]$. There are many other types of functional PIs varying according to used monomer such as photo-sensitive PI [36, 37], electrochromic PI [38], shape memory PI [39] or soluble PI [40, 41], thermoset or thermoplastic PI [42-45] and etc. The PI types, structures, properties, and uses were reviewed in Table 1.

\section{Polyimide coating}

Pls are suitable for coating applications due to adhesion to the several substrates such as metals, polymers, carbon, silica based materials (glass fiber, carbon fiber) etc. Soluble PAA precursor solutions or soluble PIs are suitable for several easy and cost-effective coating methods. It is possible to incorporate the superior properties that mentioned upper section of the PIs to the desired materials by coating method. Therefore, there are many applications related to $\mathrm{PI}$ coatings in both the literature and the industry. Sensors, spacecraft, electrical devices (batteries, displays, wires), medical devices, capillary tubes, separation membranes are some of these. Generally, aromatic PI-coated by two step method: First step is coating of polyamic acid solution on the substrate and second step is thermal or chemical imidization. $[1,13,33]$. There are several coating methods such as solution-coating, dip-coating [55], spin-coating $[56,57]$ or vapor deposition $[58,59]$, chemical deposition polymerization [47], and etc. Also new methods have been developed for PI coating on different substrates such as glow discharge vapour deposition polymerization, liquid flame spray method and etc. [60]. The coating process includes 4 steps (Fig. 2): 
Table 1 Polyimide types, structure, properties and uses

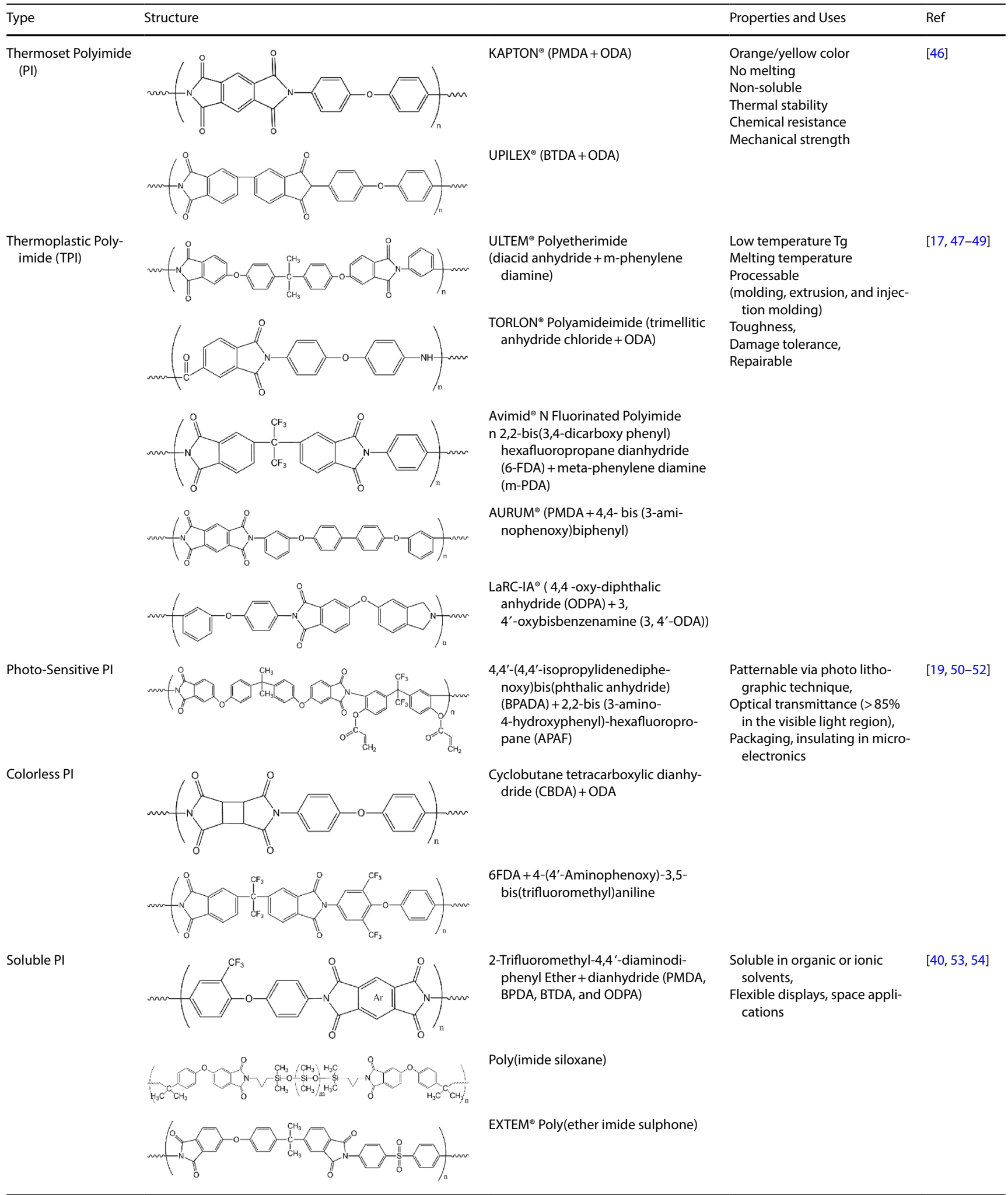


Fig. 2 Polyimide coating steps

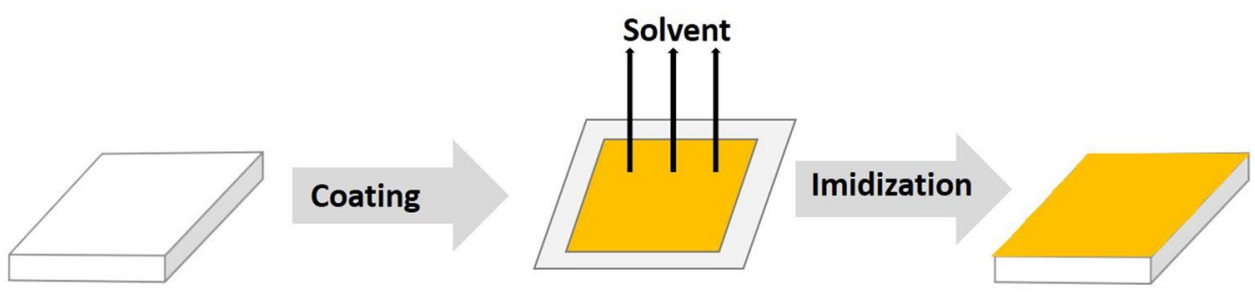

1. Substrate preparation which is elimination of impurities on the substrate surface,

2. PAA solution deposition on the substrate by mentioned methods,

3. Drying process which is removing of the solvent $\left(>150^{\circ} \mathrm{C}\right)$,

4. Curing step which is completion of imidization reaction $\left(150-400^{\circ} \mathrm{C}\right)[13,31]$.

The quality of the coating depends on production parameters and conditions, such as coating methods, drying rate and temperature, heating rate and temperature of the imidization step. The coating method and thickness affect the molecular orientation and residual stress that causes crack damages. For example, since the thickness of $\mathrm{PI}$ coating layer which was produced with solution casting method is higher than that of coated with spin-coating method, the residual stress of solution casted $\mathrm{PI}$ is lower than that of spin coated [61]. Moreover, fast evaporation of the solvent causes the thermal shrinkage. Also, the heating rate for initial and final temperatures affect the morphology of the final coating. It is possible to decrease the thermal stress by controlled and gradual heating during the imidization step [13].

\section{Applications of polyimide coatings}

PI coating onto the different substrates (metal, polimer, carbon, glass fiber etc.) provides vast opportunity to be used in wide range of applications such as sensors, electronic devices, medical analysis devices, industrial machines or buildings etc. In this section, common applications of PI coatings were reviewed.

\subsection{Sensor applications}

Optical fibers are small diameter glass fibers that widely used for telecommunication applications but recent years mostly preferred in sensing applications. Optical fibers are used in sensors, instrumental analysis devices in chemistry, diagnosis devices in the medical industry or laser systems. These fibers conduct very critical missions, so mechanical durability and functional lifetime are important for embedded optical fibers. Moreover, the repairing process is almost impossible. Also, adherence to the embedded material and resistance to process conditions are crucial. For example, optical fibers which embedded in the epoxy matrix must stand $150-200{ }^{\circ} \mathrm{C}$ curing temperature and must adhere to the epoxy matrix [62]. Commercial optical fibers consist core and central layers which are made of different glass types. Central glass layer called the cladding which is coated with acrylate resin that resistant up to $100-110^{\circ} \mathrm{C}$ which is not enough for many applications. Therefore, the cladding is coated with very thin $\mathrm{PI}$ film $(5-10 \mu \mathrm{m})$ to provide high temperature resistance up to $400^{\circ} \mathrm{C}$ and also mechanical strength such as high modulus, abrasion and static-fatique resistance [61-68]. Several patents have been focused on the improvement of PI coating for optical fiber protection. Polyimide-silicone block copolymers were developed to obtain better adhesion due to structural similarity with glass cladding and silicone groups [69]. Soluble-photocurable PI coating was developed to eliminate disadvantages of thermal imidization process such as water formation, and removal of residual solvent at high temperatures [67]. A new useful $\mathrm{PI}$ coating method was patented, low-temperature curing fluorinated-PI is coated during optical fiber drawing process occur to inhibit deterioration of optical fiber properties during coating and curing processes [68]. Dual PI coating method was developed to improve adhesion and provide elasticity, heat and moisture resistancy of optical fiber [70]. Strippable PI that can be easily stripped from the optical fiber with common, inexpensive solvents such as acetone was patented [71].

$\mathrm{PI}$ coatings are used to obtain sensor systems besides protecting against to working conditions [18]. It is not possible to produce humidity sensor from bare silica fibers since silica material is not sensitive to humidity. On the other hand, moisture sensitive Pls are hygroscopic and they show swelling when the water molecules diffuse, the swelling of the PI coating generates strain effect on the fiber. That behavior changes the Bragg condition of the Bragg grating optical fiber (FBG) and thus, provides the measurement of the relative humidity $[18,72]$. By using this property of PIs, several studies were reported in the literature [72-78] (Fig. 3). For example, Kronenberg et al. studied the effect PI coating on the sensing ability of the 


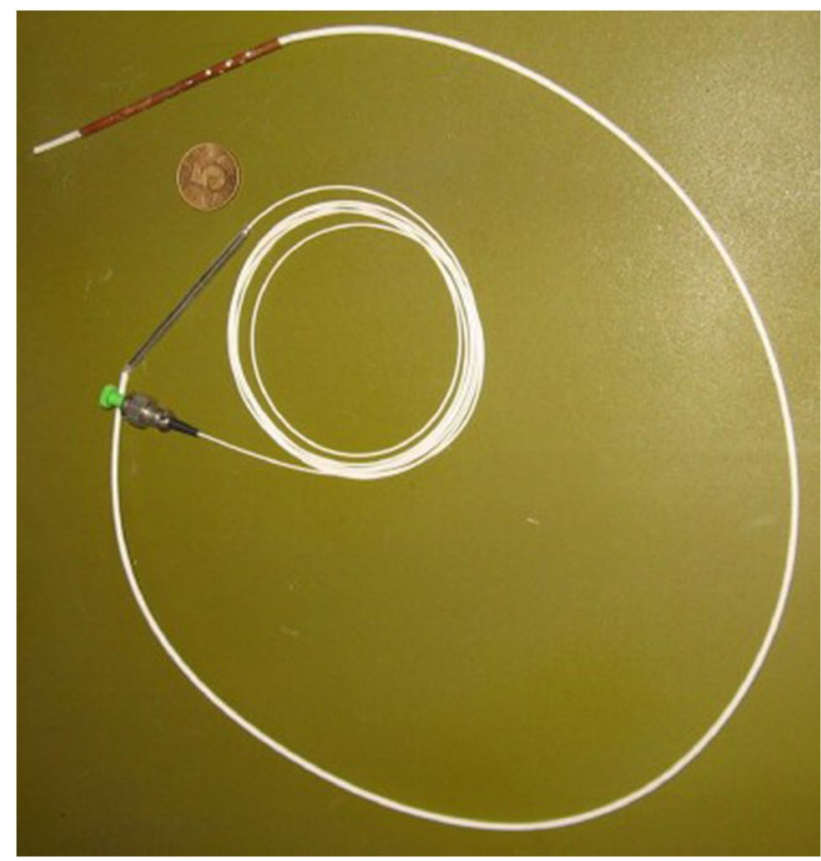

Fig. 3 PI coated RH Sensor [72]

FBGs used for intrinsic relative humidity $(\mathrm{RH})$ and temperature sensor. They have produced sensors that are sensitive to temperature and relative humidity ranges from 13 to $60^{\circ} \mathrm{C}$ and from 10 to $90 \% \mathrm{RH}$, respectively. Also, they reported that the sensitivity of the sensor increases with an increase in the PI coating thickness (from 3.6 to $29 \mu \mathrm{m}$ ) [73]. A new micro-capacitive-type relative humidity sensor with nano-grass $\mathrm{PI}$ was developed as a dielectric sensing material $[79,80]$. Pl is coated on the top of the sensor system. Then $\mathrm{PI}$ film was etched in an $\mathrm{O}_{2}$ plasma to obtain nano-grass surface. A nano-grass humidity sensor with high-performance properties was developed compared to a normal flat film type humidity sensor. Increased surface area and water affinity demonstrated a clear improvement over the normal flat-film sensor in key specifications such as quick response and sensitivity, low hysteresis, and long-term stability [79]. Besides, Yan et al. developed a soil moisture sensor with Bragg grating fiber by the help of the water sensitivity and linear expansion coefficient properties of PI layer. The designed sensor has the moisture measuring range between $15 \% \mathrm{RH} \sim 75 \% \mathrm{RH}, 12.6 \mathrm{pm} / \% \mathrm{RH}$ senstivity and $\pm 10.26 \%$ accuracy [81].

PI coated optical fibers were also developed to measure fluidic properties [82-84]. Nellen et al. presented a PI-coated FBG that measure fluid pressure and temperature in the oil-bore holes. The stability to downhole conditions and lifetime were studied with modelling and accelerated mechanical and thermal aging tests. The obtained results show that PI coated sensor withstand

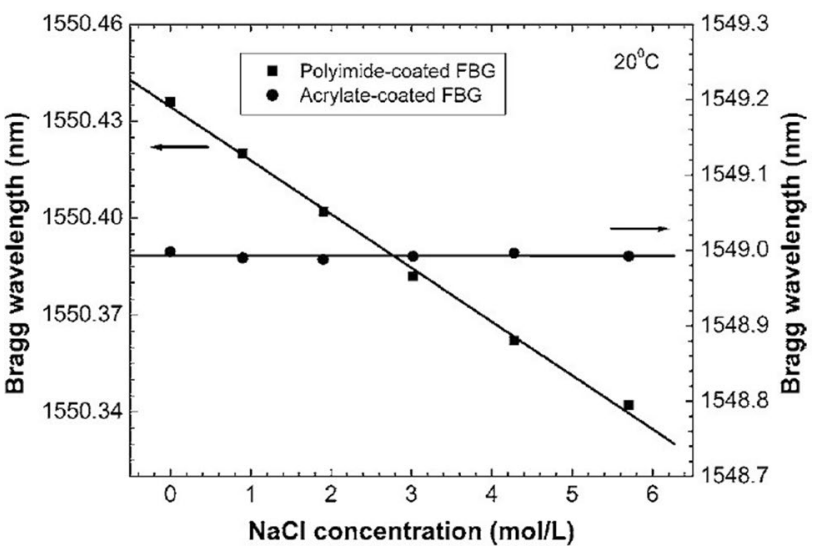

Fig. 4 Bragg wavelengths of acrylate- and polyimide-coated FBGs as functions of $\mathrm{NaCl}$ concentrations [85]

$230{ }^{\circ} \mathrm{C}$ annealing temperature and also when used at lower than $1 \mathrm{GPa}$ constant stress, the lifetime could be over 5 years [82]. Diamandi et al. coated with a new PI layer that transmit acoustic waves from the fiber cladding toward outside media while provides mechanical protection. Developed PI-coated optical fibers properly distinguish the air, ethanol and water over 100 m outside the fiber contrary to traditional optical fibers that could sense to liquids contact to the fiber [83]. Also, Chow et al. show the feasibility of the thin PI $(8 \mu \mathrm{m})$ coated optical fiber for measure the acoustic impedances of the surrounding liquids [84].

The salinity degree is crucial for production control systems or ecosystem protection. Several sensor systems have been using to measure salinity. Conventionally salinity degree is determined by measuring optical refractive index with refractometer. Although refractometer used widely, they have some disadvantages such as low sensitivity and difficult measuring due to bulky system. Optical fiber sensors have many advantages such as small size, low cost, higher sensitivity, and ability of getting response over a long distance [85]. Therefore, optical fiber sensors are preferred instead of refractometers as salinity sensors. PI coating on the optical fiber not only protect against the breakage but also, provide salinity sensing property [85]. There are several studies about development of PI coated FBG sensors for measuring salinity and temperature [85-88]. For example, Men et al. have fabricated a multiplexed PI coated fiber Bragg grating sensor for simultaneous salinity and temperature measurement. Developed sensor was compared with acrylate coated FBG sensor. The developed sensor system showed that the $\mathrm{PI}$-coated grating responds to variations of both temperature and salinity, while the acrylate-coated grating is only sensitive to the environmental temperature (Fig. 4). The experimental results 
indicated that the temperature and the salinity sensitivities of the $\mathrm{Pl}$-coated grating were $0.0094 \mathrm{~nm} /{ }^{\circ} \mathrm{C}$ and $0.0165 \mathrm{~nm} / \mathrm{M}$, respectively [85].

$\mathrm{PI}$ coated membranes can be used as a gas sensor. For example, Aslam et al. have fabricated a PI membrane for low loss microheated metal oxide (MOS) gas sensor. Generally, silicon oxide or silicon nitride used to produce this type of membranes. But the fragility of these materials reduces the yield and dielectric thickness and active area. They used thin rugged PI membrane to reduce the power consumption of a metal oxide gas sensor due to high elongation modulus and easy control layer thickness. Liquid PI (DuPont PI2575) was spin-coated on bulk micromachined silicon wafer then cured at $400{ }^{\circ} \mathrm{C}$ for $30 \mathrm{~min}$. Then Pt heating elements were added to the gas sensor system. Temperature resistance tests show that $\mathrm{Pl}$ coated heater withstand the $300{ }^{\circ} \mathrm{C}$ temperature that needed to activate the sensing layer for certain gas detection. $\mathrm{Pl}$ is a better thermal insulator and easy to deposition Pt on PI layer due to the smoother surface and adhesion property compared to oxide or nitride membranes, therefore, polyimide preferred to produce low power sensor over an oxide or nitride membranes [89]. Similar studies have been reported in the literature $[90,91]$. Flow cell test results indicate that Pl-coated sensors inhibit the effect of gases, such as carbon monoxide, acetylene, ethylene, and methane on the $\mathrm{H}_{2}$ response, dramatically improving selectivity to hydrogen compared to un-coated palladium MIS sensor (Pd-MIS) device [92]. Recently, different sensors were developed for thermal-strain sensing of rails. Two types of jacketed fibers and a carbon/polyimide coated singlemode optical fiber were used in the sytem to observe jacket effect on the thermal-strain sensing in the rail [93]. On the other hand, new studies show that it is possible to improve sensor response time and stability by addition of polar groups $(-\mathrm{COOH},-\mathrm{OH})$ to the PI structure that coated on the FBG [94]. The studies about this area continue to improve sensor sensitivity and coating quality and also to develop new sensor types.

\subsection{Electronic device and battery applications}

Electronic displays show thermal shrinkage problem under working conditions [95]. Introducing the PIs as microelectric coatings enhances mechanical strength and also thermal stability [96]. Pls are very proper polymers for electronic applications due to superior dielectric properties such as high electrical insulation (dielectric constant 3.4-3.5) [5-8], high ductility (ultimate elongation, 72\%) [8] and low thermal expansion coefficient $\left(\mathrm{CTE}, 20 \mathrm{ppm} /{ }^{\circ} \mathrm{C}\right)$ $[8,97]$. Thus, in the literature, many studies have been reported about PI coated electronic devices [98].

New polyimide-clay nanocomposite films as protective coatings were developed to protect microelectronic devices. PAA-clay nanocomposite coating solutions were prepared [99], and then, coated on a silicon wafer and glass substrate. Finally, thermal imidization at $300^{\circ} \mathrm{C}$ for $2 \mathrm{~h}$ was performed. Obtained $\mathrm{Pl}$-clay coating is suitable for protective coatings in the microelectronic area due to adhesion property to silicon substrate, besides high resistivity, low $C T E$, and low $\mathrm{O}_{2}$ permeability and water absorption, also high mechanical and dielectric strength [100]. Pl aerogel coated carbon nanotube data and power cables (Fig. 5) can be produced with carbon nanotube yarn used as conductor instead of copper wire to decrease the weight in aerospace and automotive applications and PI aerogel (foam) coated with impregnation and rollers, as light-weight dielectric insulation layer. PI aerogels were synthesized with poly (isobutylene-alt-maleic anhydride), poly(isobutylene-alt-maleic anhydride) (PMA-D) crosslinker, 4,4'-bis (4-aminophenoxy) biphenyl (BAPB) and biphenyl-3,3',4,4'- tetracarboxylic dianydride (BPDA) monomers via chemical imidization [101]. In another study, double walled CNT (DWCNT) wires and cables were produced via chemical dip coating method. The wire consists of DWCNT coated polytetrafluoroethylene (PTFE) core and $\mathrm{PI}$ insulation layer. lodine treated wire has low resistivity value as $4.510^{-6} \Omega$. m. [102].

Although the microfibrillated cellulose (MFC) sheets as biodegradable product can be used in microelectronic
Fig. 5 The images of a) LED light turns on when the clips were connected with the CNT yarns. b) LED light turns off when the clips were connected on the polyimide aerogel coatings. Reprinted with permission from [101]. Copyright 2019 American Chemical Society
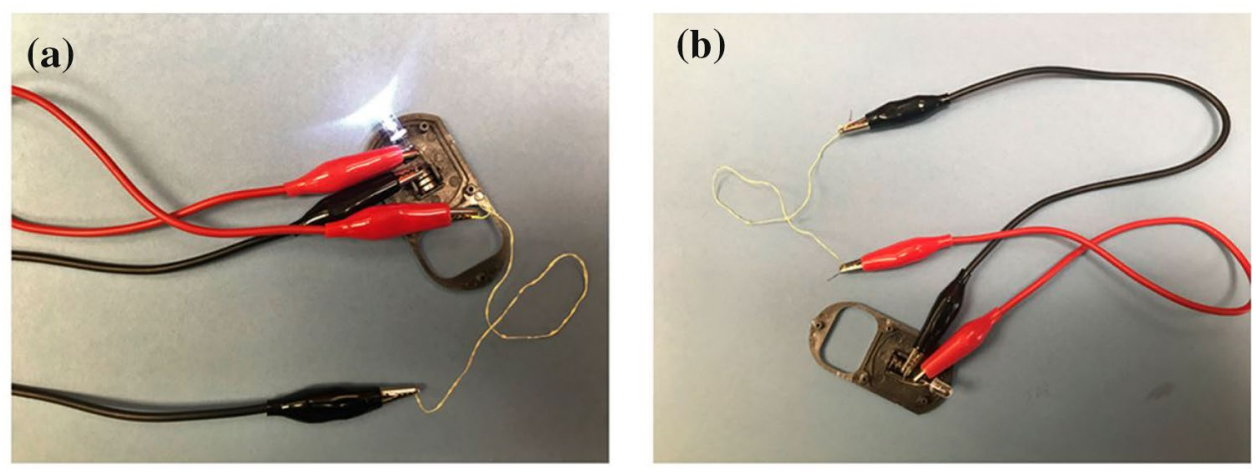
industry, MFC sheets have high surface roughness, poor dielectric properties and also, porous and hydrophilic structure which are not desired for electronic devices. Therefore, a thin PI coating on both surfaces of MFC sheets can be incorporated to improve dielectric properties for flexible substrate of an electrostatically actuated mechanical switch device. Relative permittivity was decreased from 10-70 to 3-6 [103].

There are several studies about PI coatings used in optoelectronic devices. Organic light emitting diode (OLED) displays consist an insulation layer which require certain properties. These are photosensitivity for patterning process, curability less than $250^{\circ} \mathrm{C}$ temperature, high and stable dielectric strength, thermal stability, adhesion to various substrates. A positive-tone photosensitive PI coating was developed as an insulation layer for OLED displays and compared with novalac resin and acrylic resin. After imidization at $230{ }^{\circ} \mathrm{C}$ for $30 \mathrm{~min}, \mathrm{O}_{2}$ plasma treatments (durable to this treatment no loss of film thickness after $20 \mathrm{~min}$ ) were applied to the novel coating showed better thermal (no outgas (weight loss) until $320^{\circ} \mathrm{C}$ ) and electrical properties $\left(350 \mathrm{kV} / \mathrm{mm}\right.$ after 20 days at $85^{\circ} \mathrm{C}$ ) and also, better adhesion (no peel off more than $500 \mathrm{~h}$ at $121^{\circ} \mathrm{C} 2 \times 10^{5} \mathrm{~Pa}, 100 \%$ relative humidity) on substrates (glass, ITO and $\mathrm{SiO}_{2}$ ) compared to other coating polymers. Light emiting durability tests (voltage were applied at $80^{\circ} \mathrm{C}$ for $72 \mathrm{~h}$ ) were conducted to coated OLED displays, novel PI coated OLED display did not show pixel shrinkage while novalac and acrylic resin coatings showed $64 \%$ and $47 \%$ pixel shrinkage, respectively [104]. Moreover, Chien et al. produced high response time (3.4 ms at 5.5 V) liquid crystal displays (LCD) with optically compensated bend $(\mathrm{OCB})$ cells method. They used ion-beamed PI layers to obtain lower warm up (transition) and response time. $\mathrm{Ar}^{+}$ion beam treatment increased the nucleation sites in the surface of PI, thus the transition time reduced from 24 to $17 \mathrm{~s}$ without morphological destruction. [105]. Nakano et al. developed flexible active matrix organic light emitting diode (AMOLED) displays. PI film was coated on a glass substrate with a process that is compatible with mass-production lines and than amorphous $\mathrm{In}-\mathrm{Ga}-\mathrm{Zn}-\mathrm{O}$ thin-film transistors (a-IGZOTFTs) coated on transparent PI films. Finally glass substate was removed from PI film. The results show that a-IGZO TFTs on PI film stable to annealing process at high temperature (up to $290^{\circ} \mathrm{C}$ ) [106]. Also, French et al. have developed the thinnest PI-based plastic display with a five-micron plastic substrate for the thin-film transistor (TFT) array (Fig. 6) by electronics on plastic by laser release (EPLaR) process [107].

Researchers reported molecular dynamics simulation studies to show the interfacial adhesion mechanism of PI to the silica glass for production of flexible displays. Adhesion depends on hydroxylation degree on silica glass

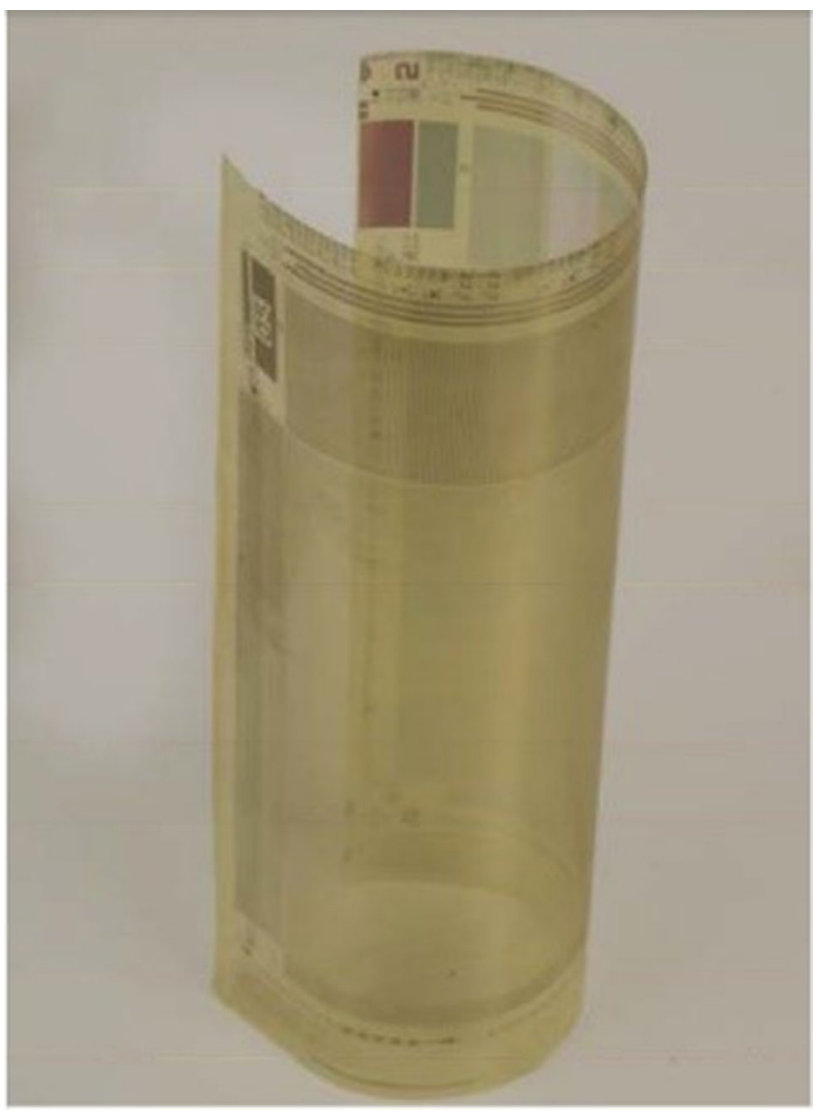

Fig. $650 \times 50 \mathrm{~mm}$ a-Si TFT array on $3 \mu \mathrm{m}$ thick freestanding polyimide layer made by the EPLaR process [107]

surface, crystallinity of silica glass, and oxygen density within PI structure. Adhesion occurs via hydrogen bonding between oxygen atoms in $\mathrm{Pl}$ and hydroxyl groups on the glass (Fig. 7a). Moreover, surface roughness increased the surface area so, more hydroxyl groups reveal and adhesion energy increases (Fig. 7b). also crystallinity of silica decreases the adhesion due to decreasing the roughness of silica surface [108-110].

Numerous patents focused on PI coating on displays for different purposes. An aqueous alkali-developable photosensitive PI precursor resin was invented for the purpose of use as highly heat-resistant transparent protection layers and insulation layers for LCD devices [111]. A new method was developed for polyimide coating on LCD panel to improve coating parameters such as cost time, quality [112]. Multi-layered PI cover film production containing optical adhesive layer with nanoscale colorant to inhibit characteristic yellow colour of the polyimide for the flexible display panel [113], soluble PI synthesis and coating for flexible displays [114] and an OLED device production with longer service life with PI base layer that improved the water and oxygen blocking performance [115] were presented as patent. 


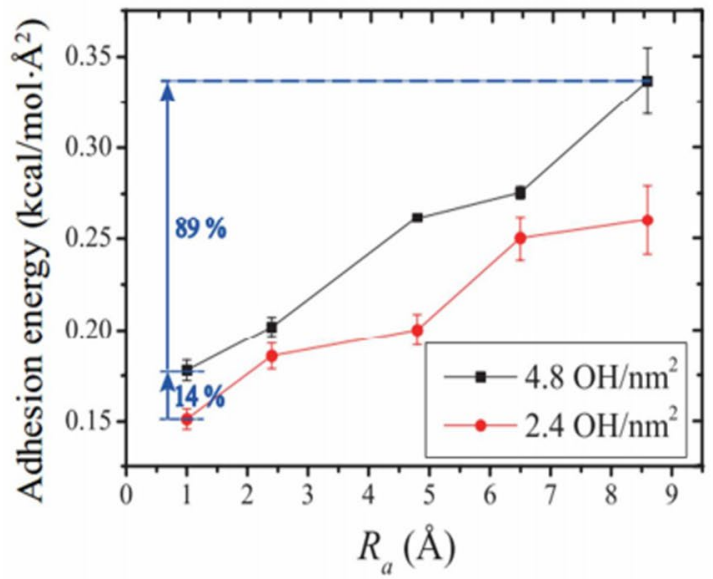

(a)

Fig. 7 Adhesion energy as a a function of average roughness (Ra) $(1.0 \sim 8.4 \AA)$ and hydroxylation density $\left(2.4\right.$ and $\left.4.8 \mathrm{OH} / \mathrm{nm}^{2}\right)$ (a), Adhesion energy, number of hydrogen bonds, surface area of

The PI coatings are also used to improve the mechanical strength and thermal shrinkage resistance in batteries. Thermal shrinkage of polyethylene separators is a crucial problem for lithium-ion batteries. Soluble co-polyimide (P84, random co-polyimides composed of 3,3',4,4'-benzophenone tetracarboxylic dianhydride (BTDA) with $80 \%$ toluene diisocyanate (TDI) and $20 \%$ methylene diphenyl diisocyanate (MDI)) was synthesized and coated on a PE separator with a dip-coating method. Optimum coating concentration was determined as 3\% (wt polymer/ wt DMF) and thickness is $23 \mu \mathrm{m}$. Heat exposure test at $140^{\circ} \mathrm{C}, 30$ min showed that the PI coating improved thermal shrinkage resistance (no shrinkage) while preserving electrochemical properties (Fig. 8) (ionic conductivity $2.43 \times 10-4 \mathrm{~S} \mathrm{~cm}^{-1}$ similar to bare PE $\left(2.54 \times 10-4 \mathrm{~S} \mathrm{~cm}^{-1}\right)$,

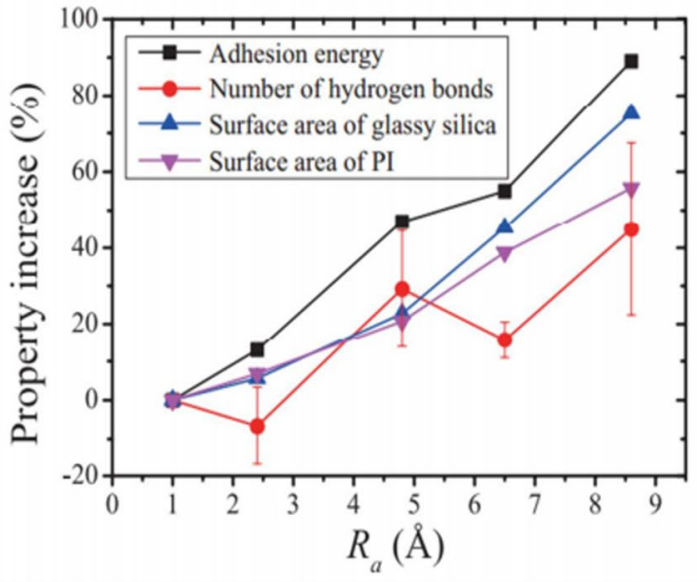

(b)

glassy silica and PI increment (\%) as a function of Ra (1.0 8.4 $)$ Reprinted with permission from [109]. Copyright (2017) American Chemical Society

(electrolyte resistance up to $4 \mathrm{~V}$ ) of the battery due to high thermal resistance of $\mathrm{PI}$ and the proper porous structure. Thermal resistance property was evaluated by open circuit voltage (OCV) measurement. $\mathrm{PI}$ coated battery resist (OCV value $4 \mathrm{~V}) 140^{\circ} \mathrm{C}$ for $110 \mathrm{~min}$ while $\mathrm{OCV}$ value of the bare PE drop $0{ }^{\circ} \mathrm{C}$ after $60 \mathrm{~min}$ [95].

Also, $\mathrm{PI}$ aerogel-polyethylene double-layer composite seperators which are temperature resistant up to $140^{\circ} \mathrm{C}$ and do not show thermal shrinkage contrary to commercial PE seperators, provide safe usage conditions against explosion and overcharging for high-safety lithium-ion batteries. Besides, coin cells with $\mathrm{PI}$ aerogel/PE separator show similar cycling and higher C-rate performances with PE seperator due to high electrolyte uptake (246\% for aerogel/PE while $136,5 \%$ for PE seperator) and wettability
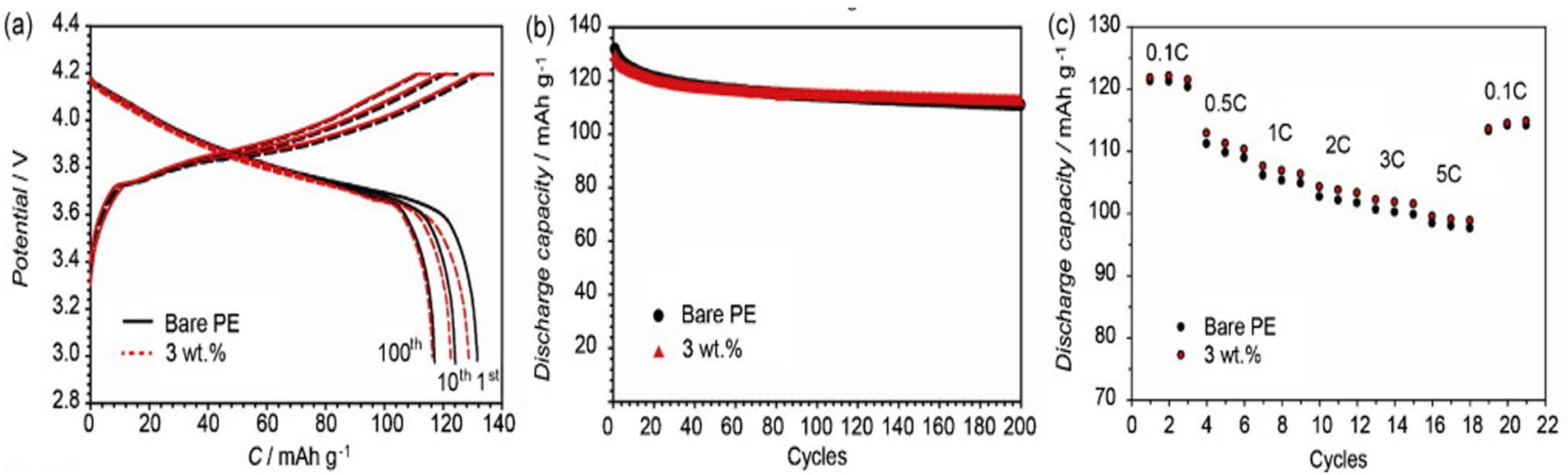

Fig. 8 Charge-discharge profiles (a), cycling performance (b), rate capability (c) of the unit cells employing the bare PE separator and the 3 wt.\% P84-coated PE separator [95] 
of seperator with electrolyte [116]. Lithium-ion batteries are used for portable electronics and electrical vehicles. Especially the spinel lithium titanate $\left(\mathrm{Li}_{4} \mathrm{Ti}_{5} \mathrm{O}_{12}\right.$, LTO) material is one of the most effective anodes for long-life and high power lithium-ion batteries. However, LTO anodes cause interfacial side reactions during charge-discharge and storage, this problem limits the wide usage lithiumion batteries. This problem can be solved by incorporating an ion conductive PI layer on the $\mathrm{Li}_{4} \mathrm{Ti}_{5} \mathrm{O}_{12}$ anode material. First, PAA precursor solution (PMDA-ODA) was synthesized and coated on the anode material. PI gel electrolyte layer was obtained after thermal imidization. The thermal resistance, ion transport property, nano-scale thickness and full protection of surface inhibit the side reactions between the partially charged LTO and liquid electrolyte (Fig. 9). Thus, the cycling and rate performance of developed lithium-ion batteries were improved [117].

By coating carbon nanotube electrode with PI layer, side reactions between electrode and electrolyte can be prevented. Thus, the cyclic performance of long-cycle Li-air batteries was improved [118]. Similarly, Yoon et al. have coated PI on carbon nanotube and prepared air electrode material. Electrochemical test results show that PI coating suppresses unwanted side reactions [119]. In a recent study, PI spheres and poly(acrylonitrile) fibers were coated on the Cu substrate and Li metal deposited to simulate Li-ion battery working condition. The results show that dual coating layer inhibit dendrite formation on the Li metal layer that negatively affect the battery performance [120]. Recently, PI coating of lithium titanate particles to reduce gas formation in the electrochemical cells were patented [121] Electrode cracking is another serious problem of lithium-ion batteries that reduces the capacity. The crack-resistant and high performance batteries can be developed by high modulus-high compressive $\mathrm{PI}$ coating on $\mathrm{SnO}_{2}$ electrode materials holding particles, in contact during charge and discharge. Moreover, the PI coating improves capacity retention and stable capacity of after 300 cycles [122]. On the other hand, silicon thin films have electrode cracking and delamination problems during cycling that causes capacity degradation. When silicon thin film electrodes capped with PI to solve mechanical degradation problem, PI layers protect the electrodes, so the battery could be used with a high
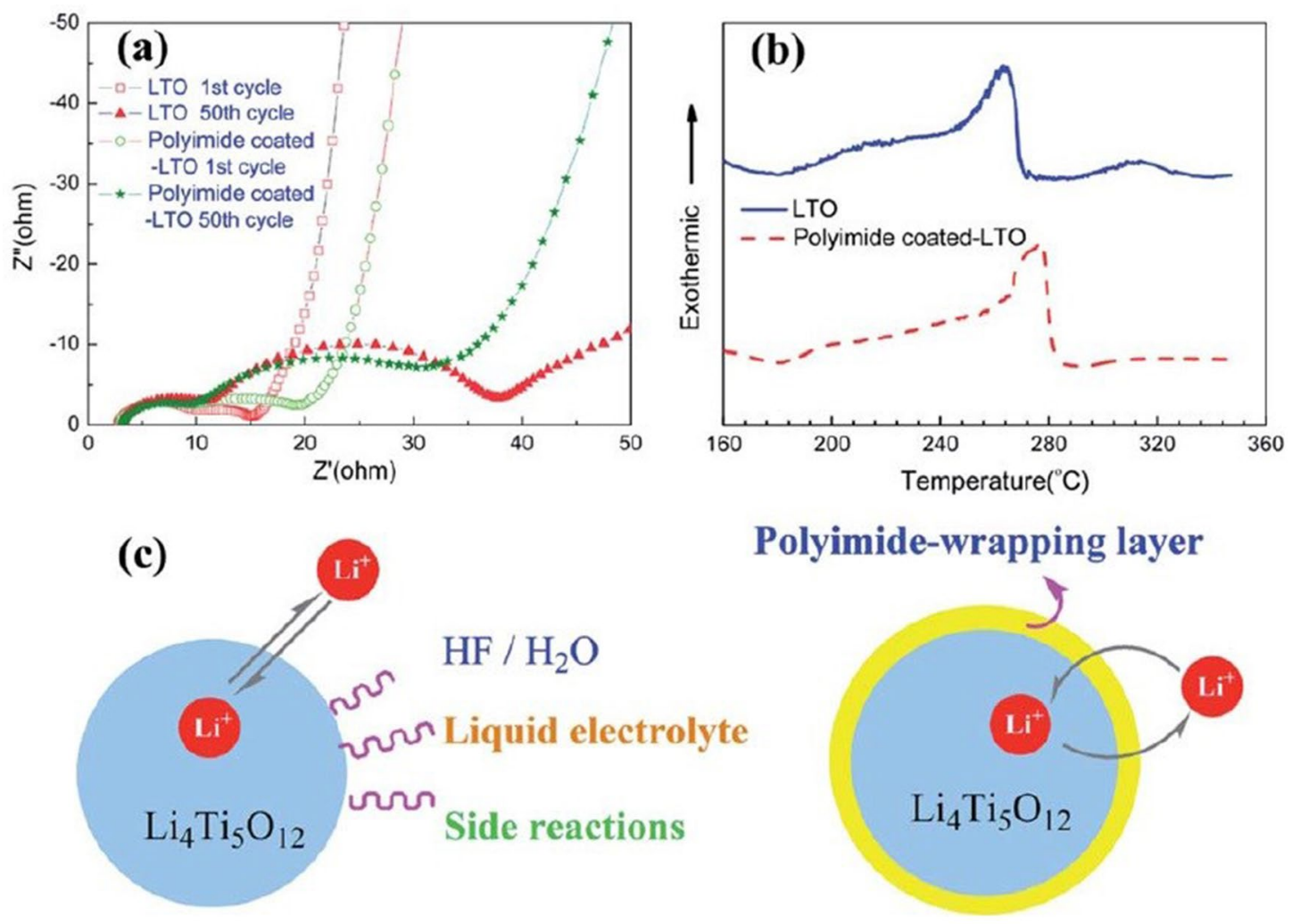

Fig. 9 a Variation in alternating current (AC) impedance spectra of cells assembled with pristine LTO and polyimide-coated LTO at 55 C; b DSC thermograms of the interfacial exothermic reaction between partially charged LTO and polyimide-coated LTO and liq- uid electrolyte; c schematic illustration of ion-conductive polyimide nanocoating layer for suppressing the interfacial side reactions. Reproduced from Ref. [117] with permission from The Royal Society of Chemistry 
capacity of $2610 \mathrm{mAh} \mathrm{g}^{-1}$ at $100 \mathrm{~mA} \mathrm{~g}^{-1}$ up to 300 cycles without capacity loss at $3500 \mathrm{~mA} \mathrm{~g}^{-1}$ [123].

The hydrophilic PI changes the resonant frequencies of the antenna with atmospheric relative humidity, so relative humidity will be measured by detecting the resonant frequencies. Therefore, PI coated Yugi-Ada antennas can be designed and analyzed for humidity sensing application. Simulation results show that this system could be alternative to existing humidity sensors [124].

Moreover, there are patents about PI coating on electrodes for production of paterning layer [125] and photolithography application [126]. On the other hand, several patents were focused on electrical wires coated with PI layer for insulation. Electrical wires have been improved over time by using low-melt PI and PAA solution to easily (melting at low temperature) repair damaged electrical wires [127], easily coatable low viscosity insulating varnish (PI precursor solution) [128], low-dielectric constant PI insulation coating [129]. Also, implantable medical device cables (lead) for electrical stimulation coated with PI providing conductor coil insulation have been developed [130].

Additionally, advanced coatings showing better UV curing ability, optical transparency, thermal stability, hardness and lower moisture uptakes respect to conventional Kapton films can be synthesized about to be used LCD, photoelectric, microelectronic applications [126, 131-133].

\subsection{Anticorrosion applications}

Polymeric coatings inhibit corrosion by physically blocking diffusion of the species such as $\mathrm{O}_{2}$ and $\mathrm{H}^{+}$[134]. NASA developed a new PI powder coating material for metal substrates such as pipes and other infrastructure components, machinery, exposed metal parts and structures, automobile components, bridges provides anti-corrosion property. PI coated metal was obtained by spray coating of the low melting point PAA and curing in powder coating oven $[135,136]$. By incorporating the layered montmorillonite clay and coating organosoluble polyimide/clay nanocomposite material on the steel substrate, anticorrosion property was enhanced. Organosoluble polyimide/ clay nanocomposite material show better corrosion resistance compared to polyaniline, poly(o-ethoxyaniline) and poly(methyl methacrylate) [134].

An electroactive $\mathrm{PI}(\mathrm{EPI})$, a promising anticorrosion material, was synthesized by reaction of amine-capped aniline trimers (1,4-phenylenediamine) and 4,4'-(4,4'-isopropylidenediphenoxy)- bis(phthalic anhydride) (BSAA) and then coated on steel as a thin layer $(20 \mu \mathrm{m})$ show advanced corrosion inhibition [55]. Huang et al. obtained effective anticorrosion coating with synthesized aniline tetramer (AT) capped electroactive imide oligomer and a polymer with electrochromic properties $[137,138]$. Corrosion resistance of EPIs can also be improved by incorporating $\mathrm{TiO}_{2}$ nanoparticles to the coating solution. While EPI layer inhibits corrosion of cold-rolled steel (CRS) electrode by the formation of a protective passivation oxide layer, $\mathrm{TiO}_{2}$ nanoparticles make complex the $\mathrm{O}_{2}$ diffusion pathway (Fig. 10) [139].

Besides, incorporation of $\mathrm{SnO}_{2}$ nanoparticles to the EPI coating improves thermal and anticorrosion properties of coating on the steel. The $\mathrm{EPI} / \mathrm{SnO}_{2}$ nanocomposites were prepared by in situ oxidative coupling polymerization of oligoaniline and thermal imidization processes. The EPI/ $\mathrm{SnO}_{2}$ nanocomposite was coated on $316 \mathrm{~L}$ stainless steel and cold rolled steel with spin coating method. The semiconductor property of both $\mathrm{SnO}_{2}$ and EPI provide synergistic effect against corrosion by redox reaction and also, $\mathrm{SnO}_{2}$ nanoparticles form a barrier to inhibit corrosive ion transition. The anticorrosion property of low nickel stainless steel (AISI 201) can be improved by incorporating copper oxide $(\mathrm{CuO})$ into the EPI by oxidative coupling polymerization followed by coating then thermal imidization [140, 141]. EPI was also synthesized to develop a biomimetic superhydrophobic surface for advanced anticorrosive coatings via nanocasting technique [142].

Beside the steel substrate, it is also possible to protect aluminum substrates by coating with polyimide [143]. Polyurea-b-polyimide (PUI) block copolymer that providing long lifetime (about 8 years), high contact angle $\left(110^{\circ}\right)$ and low surface energy (about $25.5 \mathrm{~mJ} / \mathrm{m}^{2}$ ) was synthesized

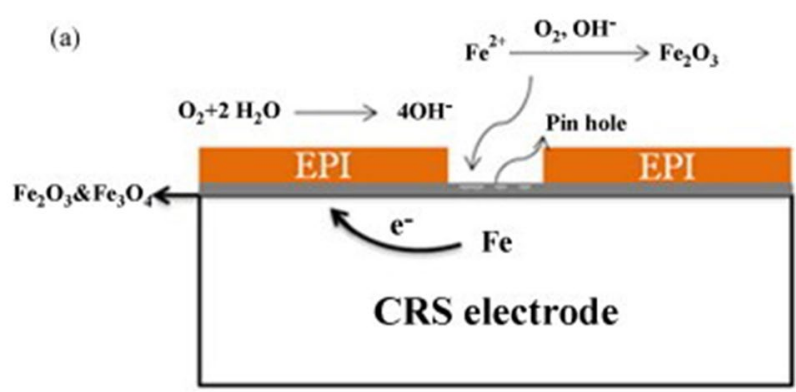

(b)

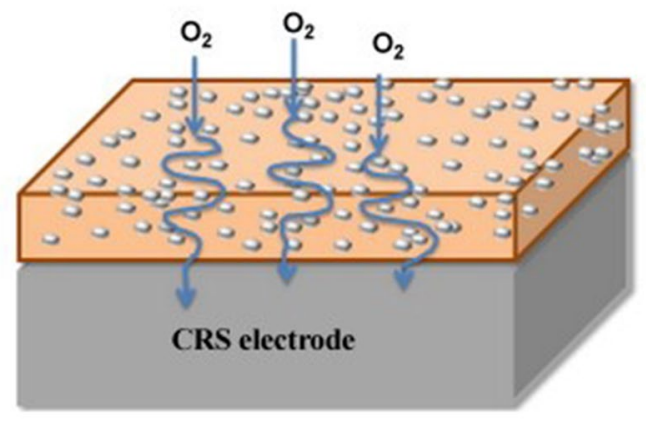

Fig. 10 Corrosion protection mechanism of the EPI (a) and TiO2 (b) layer on the steel [139] 
and coated on aluminum alloy 2024-T3 [144]. When the structure and morphology of the PUI block copolymer coatings were investigated, intra- and inter- hydrogen bonding between $\mathrm{PI}$ and polyurea macromolecules were detected. This entangled morphology provides corrosion protection by reducing surface energy and providing barrier properties. Moreover, $\mathrm{H}$-bonded imide chains avoid the hydrolysis of the ring structure in a corrosive aqueous environment [145]. Also, graphene-based PI coatings have been investigated. Chang et al. produced graphene/ EPI nanocomposite coatings that have improved anticorrosion property over EPI coating on CRS electrodes. The results show that synergistic effect of redox catalytic property of EPI and oxygen barrier property of graphene nanosheets enhanced the anticorrosion effect [146]. In order to investigate the anticorrosion property of PI with alumina-covered graphene oxide, alumina-covered graphene oxide/polyimide (AIGO/PI) nanocomposite coating material was produced by sol-gel method. Anticorrosion behavior was improved by isolating charge transfer pathway by alumina on GO [147].

\subsection{Capillary tubes}

Capillary tubes used in column chromatography devices are very brittle and sensitive to high temperatures and lose their properties when using chemicals for a long time, thus reducing the reliability of the device. In practical applications, the capillary columns are coated with flexible polymers that exhibit thermal and dimensional stability, good adhesion, mechanical flexibility, toughness, hardness to winding and abrasion, as well as chemical resistance. PIs are one of the best candidates for a high performance coating material providing the desired properties. [148]. PI coating can be applied on fused silica-capillary tubes due to flexibility, high mechanical strength, and chemical inertness. PI coated fused silica tubes are used commercially for capillary electrophoresis, capillary electrochromatography and gas chromatography [149, 150]. Novel PI copolymer including benzimidazole groups in the structure to increase thermal stability and adhesion property of the coating was developed and coated to protect intrinsically brittle quartz chromatographic columns. As a result, while $\mathrm{Tg}$ increased to $346.9^{\circ} \mathrm{C}$, CTE decreased to $24.6 \times 10-6 / \mathrm{K}$ in the range of $50-300^{\circ} \mathrm{C}$. Besides, the novel PI resist 100 cycle thermal shock test in the range of $25-320^{\circ} \mathrm{C}$ without cracking, delamination, warpage, or other failures [148].

PI coated optical fibers or capillary tubes are suitable for medical applications such as sensors, laser surgery devices or diagnosis instruments [130,151-153]. Resistance to cryogenic temperature beside high temperature is important for medical devices. Also, Pls are resistant to medical process conditions such as sterilization. On the other hand, PI coatings are inert and non-toxic, resistant to solvents and chemicals. Moreover, mechanical strength and flexibility properties of PIs make them good candidates for medical applications.

\subsection{Membrane applications}

Membranes are preferred for separation applications such as gas separation [154], water treatment [155], liquid pervaporation [156], and etc. thanks to porous structure. The thermal and chemical resistance of membranes can be enhanced by PI coating on the membrane structure [157, 158]. Moreover, PIs increase the selectivity of the membranes by adsorbing or interacting with species [159]. PIcoated composite membrane was obtained by dip coating of asymmetric polyimide membrane (as support) in PAA salt solution and imidization process. Firstly, PAA sodium salt solution was synthesized with PMDA and ODA, then mixed with trimethylamine to achieve chemical imidization. Developed PI coated composite membranes showed improved gas separation performance with the $\mathrm{CO}_{2} / \mathrm{N}_{2}$ selectivity of over 25 on gas permeation, and separation factor a $\left(\mathrm{H}_{2} \mathrm{O} / \mathrm{EtOH}\right)$ of over 800 with a total flux of $0.21 \mathrm{~kg} /$ $\mathrm{m}^{2} \mathrm{~h}$ on pervaporation [157]. Also there are studies about development of PI coated composite membranes by the solvent-less vapour deposition followed by in-situ polymerization (SLIP) technique [160].

$\mathrm{PI}$ is preferred as sorbent layer due to pi-pi stacking interaction of PI with other organic compounds or adhesion of electronegative elements ( $\mathrm{N}$ or $\mathrm{O}$ ) of $\mathrm{PI}$ structure with inorganic compounds. Therefore, $\mathrm{PI}$-coated magnetic nanoparticles can be produced as a sorbent in the solidphase extraction of polycyclic aromatic hydrocarbons such as naphthalene, anthracene, and pyrene in seawater [159].

Additionally, gas separation PI membranes by PI coating on porous polysulphone hollow fibers provides maximum gas separation performance (the $\mathrm{CO}_{2} / \mathrm{CH}_{4}$ separation factor was 30.1, and $\mathrm{CO}_{2}$ permeance was $5.7 \times 10^{-5} \mathrm{~cm}^{3}$ (STP)/ $\left(\mathrm{cm}^{2} / \mathrm{cm}\right.$. Hg.s)) respected to non-coated polysulfone membranes (the $\mathrm{CO}_{2} / \mathrm{CH}_{4}$ separation factor is 13) [161]. Recent studies have been focused on polyimide membranes rather than PI coated membranes due to higher effectivity [162-165].

\subsection{Polyimide coatings on high temperature resistant materials}

$\mathrm{PI}$ coating is a very promising application for transfer the excellent properties of Pls to various materials. The studies also focused on $\mathrm{PI}$ coatings on high temperature resistant materials due to thermal imidization process. Researchers have studied the adhesion behavior, effects of PIs, and 
different effective coating methods on several types of materials such as steel, copper, aluminum or carbon fiber.

\subsubsection{Metallic substrates}

Copper materials are widely used in electronic devices due to low cost and high electrical $\left(58.710^{6} \mathrm{~S} / \mathrm{m}\right)$ and thermal conductivity (386 W/m.K) [29]. Since copper materials are susceptible to oxidation upon exposure to high temperature or high humidity [166], protective coating to increase reliability and service life is required. In the literature, after synthesis of PMDA-ODA based PAA in NMP solvent and coating on $\mathrm{Cu}$ foil, imidization was performed by heating slowly from $150{ }^{\circ} \mathrm{C}$ to $400^{\circ} \mathrm{C}$ and adhesion behavior between polyimide and copper was investigated. The high peeling strength which is desired for microelectronic devices was reported between copper and PI [29]. The PI was studied as a binder on $\mathrm{Cu} / \mathrm{AlO}_{3}$ film to improve adhesion between $\mathrm{Cu}$ wire and other substrates of stretchable and transparent heater. The developed Cu wire/alumina/ polyimide-based transparent heater showing remarkable properties such as high temperature resistance $\left(300^{\circ} \mathrm{C}\right)$, high flexural strength by enduring 100 cycles of stretching releasing at a strain of $30 \%$ could find application in heating of future wearable optoelectronic devices [166]. The phosphinate diamine groups-contained Pls were synthesized that exhibit heat resistance, adhesion property and also, excellent hot-melt processability for flexible copper clad laminates [167].

Steel materials are often used in industrial applications, since they have high mechanical strength. However, those machine parts exposed to harsh conditions such as high friction, heat, or corrosive liquids. So, $\mathrm{PI}$ coating is one way to reduce these negative effects $[168,169]$. The liquid flame spray method that does not require thermal imidization process was applied to obtain polyimide-copper (PI-Cu) coatings on a steel substrate. Newly developed $\mathrm{PI}-\mathrm{Cu}$ coatings showing anti-fouling and anti-corrosion properties could be used in marine applications [170, 171]. PI coated stainless steel high loaded bearings can be produced by the wet coating method. When the lifetime of coated and non-coated bearings by friction test was compared, it was seen that the lifetime of uncoated bearings lasted $150 \mathrm{~h}$, while PI coated bearings lasted $500 \mathrm{~h}$. Moreover, PI coatings on steel surfaces may lower the overall consumption of lubricants due to decreasing of wear [172].

Tribological and wear properties can be improved by using polyimide/epoxy resin-polytetrafluoroethylene (PI/ EP-PTFE) bonded solid lubricant coatings filled with silver nanoparticles. Better friction and anti-wear abilities of steel materials were obtained compared to coatings with RP-3 aviation kerosene (Fig. 11) [173].

In another study, PTFE and SiC filled PI composite coatings on aluminium substrates improved the mechanical and tribological properties. The results showed that the fillers lower the friction coefficient from $0.38 \%$ to $0.18 \%$. However, wear rate decreased slightly and thermal degradation bahavior remained with same as pure $\mathrm{PI}$ coated material [27]. Cakir et al. developed PI nanocomposites that contain fluorine and $\mathrm{SiO}_{2}$ particles (perfluorooctyltriethoxysilane and tetraethyl orthosilicate) with sol-gel method. The PI nanocomposite coatings with 5-10\% reinforcement amount improved the hydrophobicity, wear and thermal resistance, adhesion, hardness and, methyl ethyl ketone solvent resistance [174]. Same group synthesized the new PI (PIF) with 6FDA (hexafluoroisopropylidene diphthalic anhydride) and/or NTDA (1,4,5,8
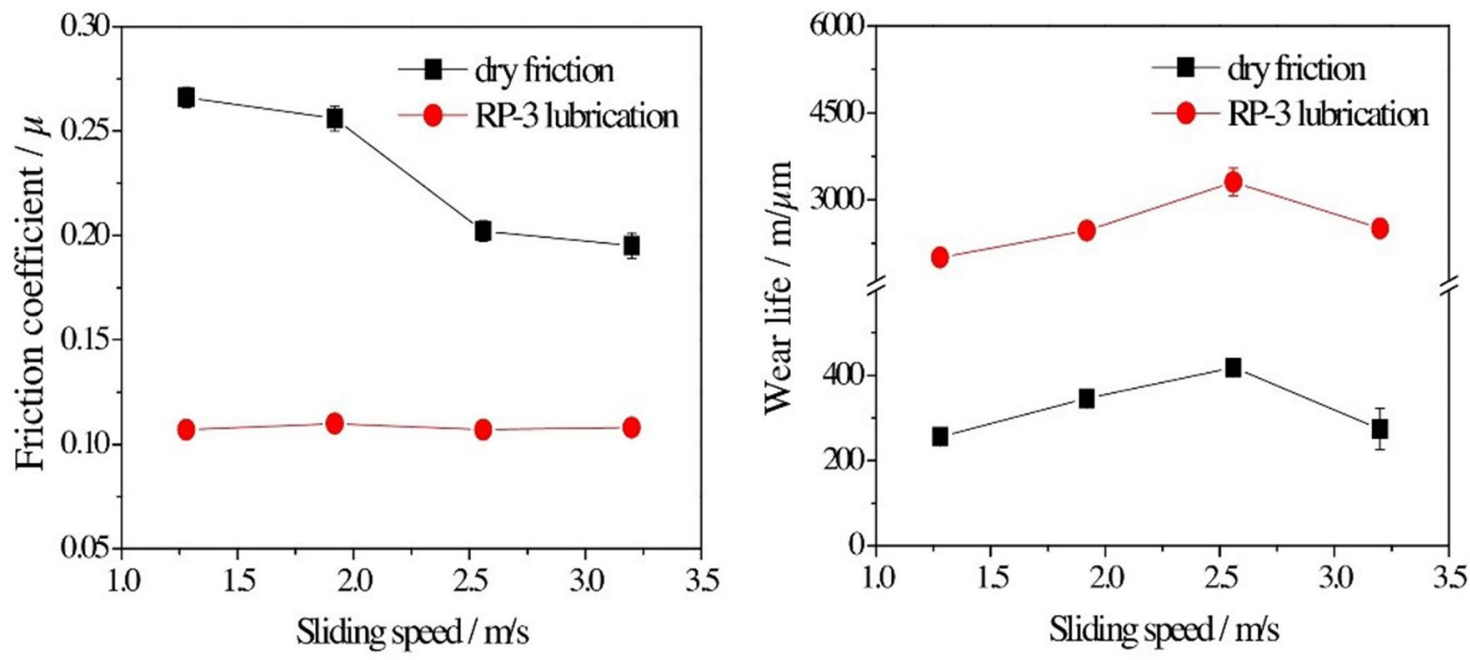

Fig. 11 Friction coefficient and wear life graphics of PI/EP-PTFE and Ag nanoparticles (RP-3 lubrication) coated steel [173] 
naphthalenetetracarboxylic dianhydride) and terminated with $1 \mathrm{H}, 1 \mathrm{H}$-perfluorooctylamine (PFOA) $(1 \%$ of the $\mathrm{PI}$ chains). Then, the PIF polymer was coated on aluminum substrates by using a $75-\mu \mathrm{m}$ wire-wound applicator and thermal imidization was conducted. The test results reveal that the properties of the PIF coating improved the glass transition temperature, thermal stability, gloss value, abrasion resistance and, pendulum hardness value when compared with neat PI coating [175].

Recently, the tribological and thermo-degradation properties of steel materials were enhanced by carbon based nanoparticles such as multi-walled carbon nanotubes (MWCNT), graphene etc. filled PI coatings [176-178].

\subsubsection{Carbon fiber}

Carbon fibers are high performance fibers that consisted at least $92 \%$ carbon atoms. These fibers are produced from different precursors such as polyacrylonitrile fiber and pitch. The production steps are high temperature oxidation, carbonization and graphitization processes [179]. Carbon fibers have high specific strength and high modulus, so they are used to produce composite materials for in aerospace, automotive, and sporting goods [180]. PIs are one of the preferred organic matrices for hybrid coatings or nanocomposites due to high thermal resistance, mechanical strength, chemical inertness and also, adhesion properties. PI coatings are applied to the carbon fibers to enhance mechanical or thermal properties of the materials.

Naganuma et al. produced PI coated carbon fibers by high temperature vapor deposition polymerization (VDP) method and thermal imidization process. Two types of PI were synthesized which are PMDA and ODA-based that coated on carbon fiber and 3,4,3',4'-benzophenone tetracarboxylic dianhydride (BTDA) and 4,4'-methylendianiline (MDA)-based that used as the matrix polymer. Mechanical tests showed that PI nano-coating $(100 \mathrm{~nm})$ improved the tensile strength (from $5.31 \pm 0.29$ to $5.76 \pm 0.25 \mathrm{GPa}$ ) and Weibull modulus (from 20.8 to 25.1 ) of the T1000GB carbon fiber (Fig. 12) [180] Similar results were obtained in another study [181]. It was reported that PI coating on carbon fibers by especially VDP coating method heals the nano-flaws on the carbon fiber, since small-sized monomers and polymers penetrate into the nano-flaws [182]. Electrophoretic deposition technique which is more economical and environmental according to VDP method is also used to provide strong adhesion mechanism between $\mathrm{PI}$ and carbon fiber due to chemical bonding and increased decomposition temperature of carbon fiber (from $330^{\circ} \mathrm{C}$ to $545^{\circ} \mathrm{C}$ ) indicating that the PI coating suppresses the oxidation of carbon fiber [183]. Organic solvent-free PI coating techniques with epoxy systems [184], photodegradation property of methylene orange [185], PI-silica hybrid colloidal composite coating which improves the thermal resistance of carbon fiber up to $600^{\circ} \mathrm{C}$ [186] and sol-gel process for polyimide coating [187] were also studied.

\subsubsection{Textiles}

By coating the PI films on different textile materials, functional properties such as high heat resistance, flame retardant and chemical resistance can be gained. Hybrid membranes were produced by coating PI nanofibers onto Kevlar fabric for protection against heat and flame. First, organo-soluble PI was synthesized from 4,4'-(4,4'-isopropylidenediphenyl-1, 1'-diyldioxy) dianiline and 4,4'-oxydiphthalic anhydride and then, obtained PI dissolved in DMF and deposited onto Kevlar fabric substrate by electrospinning method. [188]. Same technique was applied onto polyester fabrics [189]. The thermal and tensile properties of $p$-aramid yarns were improved by PI film coating by impregnation of PAA and imidization at high temperature. Lee et. al. coated
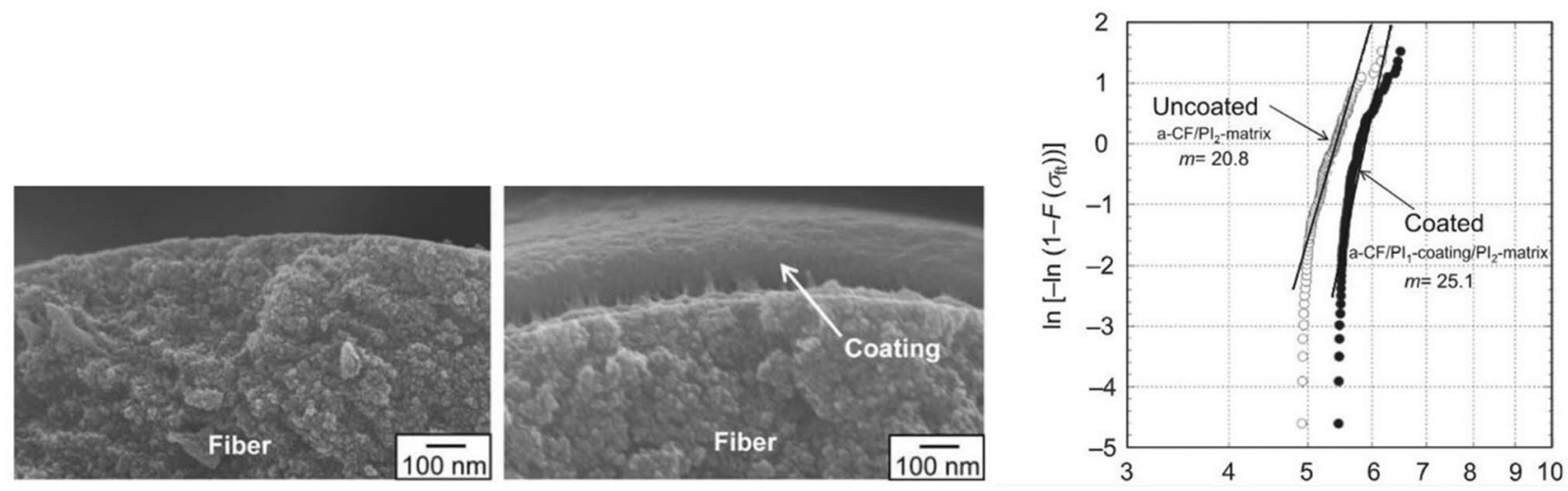

Fig. 12 SEM images and Weibull modulus graphics of the PI coated and non-coated T1000GB carbon fiber [180] 
poly $\left(\mathrm{N}, \mathrm{N}^{\prime}\right.$-bis(phenoxyphenyl)-pyromellitimide) based on PMDA and ODA onto $p$-aramid yarns with high temperature $\left(350^{\circ} \mathrm{C}\right)$ imidization process to increase tensile strength and thermal resistance [190]. Recently, Hicyilmaz et al. converted conventional fabrics to high performance textile materials by $\mathrm{PI}$ coating of polyester and cotton fabrics with low temperature imidization process (at $200^{\circ} \mathrm{C}$ ) (Fig. 13) [32]. Also flame retardant property of PI coating can be applied onto carbon-blended aluminized (E-glassbased) and non-aluminized (basofil/nomex/carbon-based) firefighting suit fabrics [191]. Furthermore, in wearable energy applications, PI coatings can be applied to provide a smooth surface in multiple layers in cotton, polyester and glass fabrics. By PI coating, surface roughness of the fabrics was decreased and the service life, performance and stability of the dye sensitized solar cells on textiles for wearable energy harvesting applications were increased [192].

\section{Commercialization of polyimide coatings and future studies}

Optical fibers were used in a wide range of area from medical instruments to industrial laser systems. These materials are very crucial and expensive parts, so they must be protected against environmental conditions. Fiberguide ${ }^{\mathrm{Tm}}$ produced PI coated optical fibers and fused silica capillary tubes that are used in medical laser, chromatography, bio-analytical sensing, spectroscopy or industrial laser system applications needed high-temperature sterilization or curing process. PI coating provides thermal and dimensional stability to the optical fibers [193]. Fibercore $^{\mathrm{TM}}$ produce high and low temperature resistance, flexible and light sensitive PI coated optical fibers. These products are used in geo-sensors, bio-medical sensors, high temperature sensors, or chemical resistance sensors [194]. Thorlabs produces high temperature resistant (up to $350^{\circ} \mathrm{C}$ ), chemical resistant, autoclavable and vacuum compatible PI coated single-mode and multimode-optical fibers, used in oil and gas sensing, aerospace, military, data communication, and medical applications [195]. iXBlue Photonics is another company that produces $\mathrm{PI}$ coated optical fibers with high temperature and radiation resistance [65]. Molex provides PI coated optical fiber and fused silica capillary tubing for medical, scientific and industrial applications [196, 197]. Zeus Inc. provides PI coated tubing and wires [198]. Hilgenberg-GMBH produce PI coated needles that are resistant to bending and cracks [199]. Aculon firm makes nanoscale PI coatings on the metal part, LCD, plasma projection scenes or industrial pipes etc. to obtain hydrophobic and oleophobic surfaces [200]. High dielectric strength PI coating material was developed for insulation of magnets, and different substrates by Composite Technology Development Inc [201]. Also different varnishes most of them based on the PAA precursor solution of $\mathrm{Pl}$ are in the market for heat resistant coatings [136, 202-207]. On the other hand, coatable PI films or tapes are in the market and commonly used for wide range of applications [8, 208-212].

Morover, PI can be coated on cooking articles to provide resistance to detergents, flame resistance and also, adhesion to an anodized support, thermal conductivity and non-sticking properties [213,214], and also, glass containers used in several areas such as pharmaceutical packages coated with PI to low-friction property [215].

With the development of technology, the interest and need for high performance polymers has increased. Pls have a wide range of applications from electronics to textiles, and the disadvantages of Pls are reduced by developing new synthesis and production methods. For example; new types of Pls, multi-functional [36, 44, 64, 101,
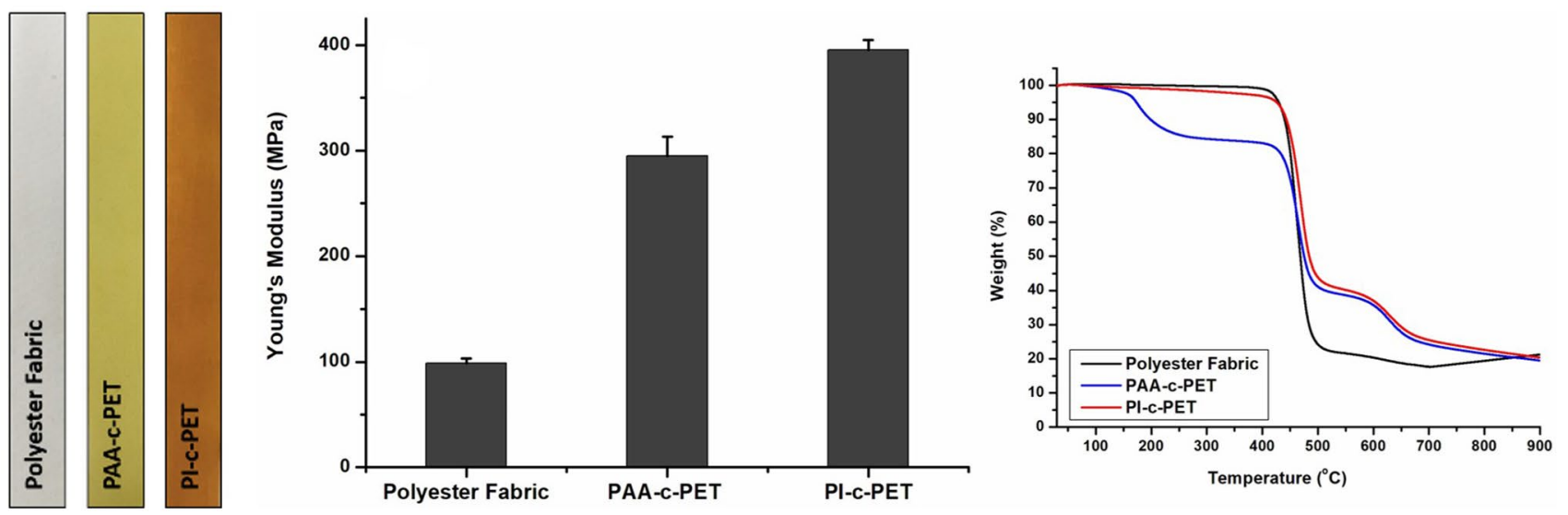

Fig. 13 Images (left), young modulus (middle) and thermal gravimetric analysis (right) graphics of non-coated, PAA and PI coated PET fabrics [32] 
216-218], soluble [175, 219, 220] and colorless [221-226] were produced. Furthermore, the properties of PI polymers are further enhanced by the addition of functional micro and nanoparticles such as metal oxides [140,227-229] and graphene derivatives [230-233]. In recent years, studies have been focused on the synthesis of special PIs for the desired properties [64,230], as well as the development of low-cost polymer production and coating methods [234]. These developments will expand the application area of the PI coated materials.

\section{Conclusion}

In this review, the most common coating applications of Pls are summarized, the coating methods and the effects of PIs on coated materials are explained in depth. PI is an important polymer for technical coating applications due to its superior thermal resistance, resistance to external factors and mechanical properties in a wide range of properties. Pls can be applied to various substrates such as various fibers (optical fibers, carbon fibers etc.), metal sheets / wires and textile materials to increase their temperature resistance, corrosion-wear resistance and mechanical strength. It can be used in microelectronic devices and batteries, gas separation systems, medical devices in order to provide insulation against environmental conditions and protection against working conditions, and also in sensor systems for determination of humidity, temperature and salinity. In this context, researchers are working with micro / nanoparticle additives or various synthesis techniques to develop new PI coatings. Especially new coating methods pave the way for the development of high-tech products that require high temperatures in applications such as space. In addition, Pl aerogels, foams, membranes and nanocomposites with multifunctional properties have come to the fore in applications in recent years. As a result, future work on PI coatings will focus more on new multifunctional new coating applications and advanced materials including the synthesis of new additives and new types of polyimides.

\section{Compliance with ethical standards}

Conflict of interest On behalf of all authors, the corresponding author states that there is no conflict of interest.

Open Access This article is licensed under a Creative Commons Attribution 4.0 International License, which permits use, sharing, adaptation, distribution and reproduction in any medium or format, as long as you give appropriate credit to the original author(s) and the source, provide a link to the Creative Commons licence, and indicate if changes were made. The images or other third party material in this article are included in the article's Creative Commons licence, unless indicated otherwise in a credit line to the material. If material is not included in the article's Creative Commons licence and your intended use is not permitted by statutory regulation or exceeds the permitted use, you will need to obtain permission directly from the copyright holder. To view a copy of this licence, visit http://creativecommons .org/licenses/by/4.0/.

\section{References}

1. Thiruvasagam $P$ (2013) Synthesis and characterization of $A B-$ type monomers and polyimides: a review. Des Monomers Polym 16(3):197-221

2. Qu C, Hu J, Liu X, Li Z, Ding Y (2017) Morphology and mechanical properties of polyimide films: the effects of UV irradiation on microscale surface. Materials 10(11):1329

3. Huo H, Mo S, Sun H, Yang S, Fan L (2011) Synthesis of phthalic end-capped copolyimides and their adhesive properties. High Perform Polym 23(5):374-383

4. Gouzman I, Grossman E, Verker R, Atar N, Bolker A, Eliaz N (2019) Advances in polyimide-based materials for space applications. Adv Mater 31(18):1807738

5. Sugimoto $E$ (1989) Applications of polyimide films to the electrical and electronic industries in Japan. IEEE Electr Insul Mag 5(1):15-23

6. Gao H, Lan X, Liu L, Xiao X, Liu Y, Leng J (2017) Study on performances of colorless and transparent shape memory polyimide film in space thermal cycling, atomic oxygen and ultraviolet irradiation environments. Smart Mater Struct 26(9):095001

7. Hsiao Y-S, Whang W-T, Wu S-C, Chuang K-R (2008) Chemical formation of palladium-free surface-nickelized polyimide film for flexible electronics. Thin Solid Films 516(12):4258-4266

8. DuPont DuPont ${ }^{\mathrm{TM}}$ Kapton $^{\circledast}$ polyimide film https://www.dupon t.com/content/dam/dupont/products-and-services/membr anes-and-films/polyimde-films/documents/DEC-Kapto n-summary-of-properties.pdf. Accessed 10.09.2019 2019

9. Karim KS, Abbaszadeh S (2016) Radiation detector system and method of manufacture. United States Patent US9269838B2.

10. Clair AKS, Clair TLS (1986) Process for preparing highly optically transparent/colorless aromatic polyimide film. United States Patent US4603061A.

11. Xiao T, Fan X, Fan D, Li Q (2017) High thermal conductivity and low absorptivity/emissivity properties of transparent fluorinated polyimide films. Polym Bull 74(11):4561-4575

12. Chen KM, Ho SM, Wang TH, King JS, Chang WC, Cheng R, Hung A (1992) Studies on the adhesion of polyimide coatings on copper foil. J Appl Polym Sci 45(6):947-956

13. Ghosh MK (1996) Polyimides: fundamentals and applications CRC Press, New York

14. Feger C (1993) Advances in polyimide: science and technology. CRC Press, Florida

15. Ni H-j, Liu J-g, Wang Z-h, Yang S-y (2015) A review on colorless and optically transparent polyimide films: Chemistry, process and engineering applications. J Ind Eng Chem 28:16-27

16. Liaw D-J, Wang K-L, Huang Y-C, Lee K-R, Lai J-Y, Ha C-S (2012) Advanced polyimide materials: syntheses, physical properties and applications. Prog Polym Sci 37(7):907-974

17. Feng X, Liu J (2018) Thermoplastic Polyimide (TPI). In: Visakh PM, Semkin AO (eds) High performance polymers and their nanocomposites. Wiley, Beverly. pp 149-219. doi:https://doi. org/10.1002/9781119363910.ch6

18. Abadie MJM (2012) High performance polymers-polyimides based: from chemistry to applications. InTech Rijeka, Croatia 
19. Yi C, Li W, Shi S, He K, Ma P, Chen M, Yang C (2020) High-temperature-resistant and colorless polyimide: Preparations, properties, and applications. Sol Energy 195:340-354

20. Ji D, Li T, Hu W, Fuchs H (2019) Recent progress in aromatic polyimide dielectrics for organic electronic devices and circuits. Adv Mater 31(15):1806070

21. Ohya H, Kudryavsev V, Semenova SI (1997) Polyimide membranes: applications, fabrications and properties. CRC Press, Florida

22. Ma P, Dai C, Wang H, Li Z, Liu H, Li W, Yang C (2019) A review on high temperature resistant polyimide films: heterocyclic structures and nanocomposites. Compos Commun 16:84-93

23. Favvas EP, Katsaros FK, Papageorgiou SK, Sapalidis AA, Mitropoulos AC (2017) A review of the latest development of polyimide based membranes for $\mathrm{CO} 2$ separations. React Funct Polym 120:104-130

24. Liu J-g, Zhang X-m, Chen F-x, Tong W-s, Zhang Y-H (2017) A Review on Recent Progress of Research and Applications for Polyimide Aerogels. In: Murphy C (ed) Polyimides, Synthesis. Application and Research Nova Sciences Publishers Inc., New York, $\mathrm{p} 105$

25. Hergenrother PM (2003) The use, design, synthesis, and properties of high performance/high temperature polymers: an overview. High Perform Polym 15(1):3-45

26. Zhang X, Yan X, Shi M (2017) The flame retardancy and pyrolysis mechanism of polyimide fibers investigated by cone calorimeter and pyrolysis-gas chromatography-mass spectrometry. J Ind Text 48(2):465-481

27. Demian C, Liao H, Lachat R, Costil S (2013) Investigation of surface properties and mechanical and tribological behaviors of polyimide based composite coatings. Surf Coat Technol 235:603-610

28. Kim YH, Kim J, Walker GF, Feger C, Kowalczyk SP (1988) Adhesion and interface investigation of polyimide on metals. J Adhes Sci Technol 2(1):95-105

29. Kim YH, Walker GF, Kim J, Park J (1987) Adhesion and interface studies between copper and polyimide. J Adhes Sci Technol 1(1):331-339

30. Wright WW, Hallden-Abberton M (2000) Polyimides. In: UIImann's Encyclopedia of Industrial Chemistry.

31. Chen W, Chen W, Zhang B, Yang S, Liu C-Y (2017) Thermal imidization process of polyimide film: interplay between solvent evaporation and imidization. Polymer 109:205-215

32. Sezer Hicyilmaz A, Altin Y, Bedeloglu A (2019) Polyimide-coated fabrics with multifunctional properties: flame retardant, UV protective, and water proof. J Appl Polym Sci 136(23):47616

33. Yang W-k, Liu F-f, Li G-m, Zhang E-s, Xue Y-h, Dong Z-x, Qiu X-p, Ji X-I (2016) Comparison of different methods for determining the imidization degree of polyimide fibers. Chin J Polym Sci 34(2):209-220

34. Yun C, Shin B, Kim K, Suh JS (2019) Polyimide precursor solution and method for producing same. US Patent US20190048141A1.

35. Yun C, Shin B, Jeong HW, Kim K, Park H (2020) Polyimide-based solution and polyimide-based film produced using same. US Patent US10647883B2.

36. Qu L, Tang L, Bei R, Zhao J, Chi Z, Liu S, Chen X, Aldred MP, Zhang Y, Xu J (2018) Flexible multifunctional aromatic polyimide film: highly efficient photoluminescence, resistive switching characteristic, and electroluminescence. ACS Appl Mater Interfaces 10(14):11430-11435

37. Bernd KA (1989) Conformal Coatings and Encapsulants. In: Cyril AD (ed) Electronic Materials Handbook: Packaging, vol 1. ASM International, Ohio, pp 759-866

38. Chang C-H, Wang K-L, Jiang J-C, Liaw D-J, Lee K-R, Lai J-Y, Lai $\mathrm{K}-\mathrm{H}$ (2010) Novel rapid switching and bleaching electrochromic polyimides containing triarylamine with 2-phenyl-2-isopropyl groups. Polymer 51(20):4493-4502

39. Xiao X, Kong D, Qiu X, Zhang W, Liu Y, Zhang S, Zhang F, Hu $Y$, Leng J (2015) Shape memory polymers with high and low temperature resistant properties. Sci Rep 5:14137

40. Chung IS, Kim SY (2000) Soluble polyimides from unsymmetrical diamine with trifluoromethyl pendent group. Macromolecules 33(9):3190-3193

41. Chen Y, Huang R, Zhang Q, Sun W, Liu X (2017) Synthesis and properties of highly soluble branched polyimide based on 2 , 4, 6-triaminopyrimidine. High Perform Polym 29(1):68-76

42. Lee Y, Gungor A, Yoon T, McGrath J (1995) Adhesive and thermo-mechanical behavior of phosphorus-containing thermoplastic polyimides. J Adhes 55(1-2):165-177

43. Staudt-Bickel C, Koros WJ (1999) Improvement of CO2/CH4 separation characteristics of polyimides by chemical crosslinking. J Membr Sci 155(1):145-154

44. Hu J, Wang J, Qi S, Tian G, Wu D (2019) Thermoplastic and soluble co-polyimide resins fabricated via the incorporation of 2, 3, 3', 4'-biphenyltetracarboxylic dianhydride. High Perform Polym 31(9-10):1272-1279

45. Visakh P, Semkin AO (2018) High performance polymers and their nanocomposites. Wiley, New Jersey

46. Mazzold P, Carturan S, Quaranta A, Sada C, Sglavo V (2013) Ion exchange process: history, evolution and applications. La Rivista del Nuovo Cimento 36:397-460

47. Wilson D, Stenzenberger HD, Hergenrother PM (1990) Polyimides. Springer, New York

48. Melton GH, Peters EN, Arisman RK (2011) 2 - Engineering Thermoplastics. In: Kutz M (ed) Applied Plastics Engineering Handbook. William Andrew Publishing, Oxford. pp 7-21. https://doi. org/10.1016/B978-1-4377-3514-7.10002-9

49. Nicolais L, Boyd J, Pratte J (2012) Partially Fluorinated Polyimide Resins and Composites. In: Nicolais L (ed) Wiley Encyclopedia of Composites. Wiley, New Jersey, pp 1-13. https://doi. org/10.1002/9781118097298.weoc185

50. Qi L, Guo C-Y, Huang Fu M-G, Zhang Y, Yin L-m, Wu L, Liu J-g, Zhang X-m (2019) Enhancement of solvent resistance of polyimide electrospun mat via the UV-Assisted electrospinning and photosensitive Varnish. Polymers 11(12):2055

51. Fukukawa K-i, Ueda M (2008) Recent progress of photosensitive polyimides. Polym J 40(4):281-296

52. Tomikawa M, Okuda R, Ohnishi H (2015) Photosensitive polyimide for packaging applications. J Photopolym Sci Technol 28(1):73-77

53. Ghosh A, Sen SK, Banerjee S, Voit B (2012) Solubility improvements in aromatic polyimides by macromolecular engineering. RCS Adv 2(14):5900-5926

54. Kim D, Nunes SP (2017) Poly (ether imide sulfone) membranes from solutions in ionic liquids. Ind Eng Chem Res 56(50):14914-14922

55. Huang K-Y, Jhuo Y-S, Wu P-S, Lin C-H, Yu Y-H, Yeh J-M (2009) Electrochemical studies for the electroactivity of aminecapped aniline trimer on the anticorrosion effect of as-prepared polyimide coatings. Eur Polym J 45(2):485-493

56. Jenekhe SA (1983) The rheology and spin coating of polyimide solutions. Polym Eng Sci 23(15):830-834

57. Bernd KA (1989) Hybrids and Higher-Level Integration. In: Cyril AD (ed) Electronic Materials Handbook: Packaging, vol 1. ASM International, Ohio.

58. Salem JR, Sequeda FO, Duran J, Lee WY, Yang RM (1986) Solventless polyimide films by vapor deposition. J Vac Sci Technol A 4(3):369-374

59. Iijima M, Takahashi Y, (1993) Electrical, thermal and mechanical properties of polyimide thin films prepared by 
high-temperature vapor deposition polymerization. High Perform Polym 5(3):229-237

60. Maggioni G, Carturan S, Rigato V, Della Mea G (2001) Glow discharge vapour deposition polymerisation of polyimide thin coatings. Surf Coat Technol 142:156-162

61. Coburn JC, Pottiger MT, Noe SC, Senturia SD (1994) Stress in polyimide coatings. J Polym Sci Part B Polym Phys 32(7):1271-1283

62. Skontorp A (2000) Strength and failure mechanisms of polyimide-coated optical fibers. Smart Structures and Materials 2000: Sensory Phenomena and Measurement Instrumentation for Smart Structures and Materials. International Society for Optics and Photonics, Washington, pp 240-252

63. Dikshit AK (2016) Continuous flow of polyimide coating on silica optical fibre and its characterization. Int J Plast Technol 20(2):401-423

64. Zhang Y, Qu L, Liu J, Wu X, Zhang Y, Zhang R, Qi H, Zhang X (2019) Synthesis and characterization of high-temperatureresistant and optically transparent polyimide coatings for potential applications in quartz optical fibers protection. J Coat Technol Res 16(2):511-520

65. iXBlue-Photonics (2020) Polyimide Fibers Fibers for Space \& Nuclear Environment. https://photonics.ixblue.com/store/optic al-sensors-fibers/polyimide-fibers. Accessed 14.04.2020 2020

66. Molex (2009) Polymer Coatings for Silica Optical Fiber. https ://www.molex.com/mx_upload/superfamily/polymicro/pdfs/ Polymer_Coatings_for_Silica_Optical_Fiber_Nov_2009.pdf. Accessed 15.04.2020 2020

67. Ngo DD, Cahill PJ, Greczek JJ (1996) Photocurable polyimide coated glass fiber. US Patent US5504830A.

68. Vacha L, Melling PJ (1996) Polyimide coated heavy metal fluoride glass fiber and method of manufacture. US Patent US5567219A.

69. Urruti EH (1989) Method of coating and optical fiber comprising polyimide-silicone block copolymer coating. US Patent US4848869A.

70. Bennett KW, Koh J (2015) Dual coated optical fibers and methods for forming the same. US Patent US9063268B2.

71. Vacha LJ (1998) Method of forming a strippable polyimide coating for an optical fiber. US Patent US5714196A.

72. Huang X, Sheng D, Cen K, Zhou H (2007) Low-cost relative humidity sensor based on thermoplastic polyimide-coated fiber Bragg grating. Sens Actuators B Chem 127(2):518-524

73. Kronenberg P, Rastogi PK, Giaccari P, Limberger HG (2002) Relative humidity sensor with optical fiber Bragg gratings. Opt Lett 27(16):1385-1387

74. Arregui FJ, Matías IR, Cooper KL, Claus RO (2002) Simultaneous measurement of humidity and temperature by combining a reflective intensity-based optical fiber sensor and a fiber Bragg grating. IEEE Sens J 2(5):482-487

75. Lin Y, Gong Y, Wu Y, Wu H (2015) Polyimide-coated fiber Bragg grating for relative humidity sensing. Photonic Sens 5(1):60-66

76. Berruti G, Consales M, Giordano M, Sansone L, Petagna P, Buontempo S, Breglio G, Cusano A (2013) Radiation hard humidity sensors for high energy physics applications using polyimidecoated fiber Bragg gratings sensors. Sens Actuators B Chem 177:94-102

77. Bai W, Yang M, Dai J, Yu H, Wang G, Qi C (2016) Novel polyimide coated fiber Bragg grating sensing network for relative humidity measurements. Opt Express 24(4):3230-3237

78. Chai J, Liu Q, Liu J, Zhang D (2018) Optical fiber sensors based on novel polyimide for humidity monitoring of building materials. Opt Fiber Technol 41:40-47

79. Lee H, Lee S, Jung S, Lee J (2011) Nano-grass polyimide-based humidity sensors. Sens Actuators B Chem 154(1):2-8
80. Boudaden J, SteinmaßI M, Endres H-E, Drost A, Eisele I, Kutter C, Müller-Buschbaum P (2018) Polyimide-Based Capacitive Humidity Sensor. Sensors 18(5):1516

81. Yan K, Liu J, Sun N, Zhong W Soil moisture sensor design based on fiber Bragg grating. In: Tenth International Symposium on Precision Engineering Measurements and Instrumentation, 2019. International Society for Optics and Photonics, $p 1105326$

82. Nellen PM, Mauron P, Frank A, Sennhauser U, Bohnert K, Pequignot $\mathrm{P}$, Bodor $\mathrm{P}$, Brändle $\mathrm{H}$ (2003) Reliability of fiber Bragg grating based sensors for downhole applications. Sens Actuators A Phys 103(3):364-376

83. Diamandi HH, London Y, Bashan G, Zadok A (2019) Distributed opto-mechanical analysis of liquids outside standard fibers coated with polyimide. APL Photonics 4(1):016105

84. Chow DM, Thévenaz $L$ (2018) Forward Brillouin scattering acoustic impedance sensor using thin polyimide-coated fiber. Opt Lett 43(21):5467-5470

85. Men L, Lu P, Chen Q (2008) A multiplexed fiber Bragg grating sensor for simultaneous salinity and temperature measurement. J Appl Phys 103(5):053107

86. Wu C, Guan B-O, Lu C, Tam H-Y (2011) Salinity sensor based on polyimide-coated photonic crystal fiber. Opt Express 19(21):20003-20008

87. Luo D, Ma J, Ibrahim Z, Ismail Z (2017) Etched FBG coated with polyimide for simultaneous detection the salinity and temperature. Opt Commun 392:218-222

88. Sun M-Y, Jiang H-T, Shi B, Zhou G-Y, Inyang HI, Feng C-X (2019) Development of FBG salinity sensor coated with lamellar polyimide and experimental study on salinity measurement of gravel aquifer. Measurement 140:526-537

89. Aslam M, Gregory C, Hatfield J (2004) Polyimide membrane for micro-heated gas sensor array. Sens Actuators B Chem 103(1-2):153-157

90. Briand D, Colin S, Gangadharaiah A, Vela E, Dubois P, Thiery L, De Rooij NF (2006) Micro-hotplates on polyimide for sensors and actuators. Sens Actuators A Phys 132(1):317-324

91. Briand D, Colin S, Courbat J, Raible S, Kappler J, De Rooij N (2008) Integration of MOX gas sensors on polyimide hotplates. Sens Actuators B Chem 130(1):430-435

92. Li D, McDaniel A, Bastasz R, Medlin J (2006) Effects of a polyimide coating on the hydrogen selectivity of MIS sensors. Sens Actuators B Chem 115(1):86-92

93. Gu L, Zhang L, Bao X, Zhang M, Zhang C, Dong Y (2018) Detection of thermal strain in steel rails with BOTDA. Appl Sci. 8(11):2013

94. Wu H, Sun T, Peng J, Dai J, Yang M (2020) Polar-groups-modified polyimide based on a fiber Bragg grating for relative humidity sensors. Appl Opt 59(8):2468-2473

95. Song J, Ryou M-H, Son B, Lee J-N, Lee DJ, Lee YM, Choi JW, Park J-K (2012) Co-polyimide-coated polyethylene separators for enhanced thermal stability of lithium ion batteries. Electrochim Acta 85:524-530

96. Beuhler AJ, Burgess MJ, Fjare DE, Gaudette JM, Roginski RT (1989) Moisture and purity in polyimide coatings. MRS Proceedings $154: 73$

97. Sidorov V, Shai A, Ritter D, Paz Y (1999) Polyimide coating on non-planar microelectronic devices: characterization of vacuum drying effects by a new'flip-paste'back-etching method. Surf Coat Technol 122(2-3):214-218

98. Lee Y, Craig J, Pye W 1982 Polyimide coatings for microelectronic applications. In: Polymer Materials for Electronic Applications, ACS Symposium Series, ACS Publications, Washington.

99. Magaraphan R, Lilayuthalert W, Sirivat A, Schwank JW (2001) Preparation, structure, properties and thermal behavior of rigid-rod polyimide/montmorillonite nanocomposites. Compos Sci Technol 61(9):1253-1264 
100. Khayankarn O, Magaraphan R, Schwank JW (2003) Adhesion and permeability of polyimide-clay nanocomposite films for protective coatings. J Appl Polym Sci 89(11):2875-2881

101. Guo H, Dewey O, McCorkle LS, Meador MAB, Pasquali M (2019) Polyimide aerogels as lightweight dielectric insulators for carbon nanotube cables. ACS Appl Polym Mater 1(7):1680-1688

102. Xie C, Yang S, Shi J, Li X, Niu C (2019) A double-walled carbon nanotubes conducting wire prepared by dip-coating. Mater Res Express. 6(9):0950b0957.

103. Couderc S, Ducloux O, Kim B, Someya T (2009) A mechanical switch device made of a polyimide-coated microfibrillated cellulose sheet. J Micromech Microeng 19(5):055006

104. Okuda R, Miyoshi K, Arai N, Tomikawa M (2004) Polyimide coatings for OLED applications. J Photopolym Sci Technol 17(2):207-213

105. Chien H, Wu G, Chiue C, Chen C (2011) Surface modification of polyimide alignment films by ion beams for liquid crystal displays. Surf Coat Technol 206(5):797-800

106. Nakano S, Saito N, Miura K, Sakano T, Ueda T, Sugi K, Yamaguchi H, Amemiya I, Hiramatsu M, Ishida A (2012) Highly reliable a-IGZOTFTs on a plastic substrate for flexible AMOLED displays. J Soc Inf Display 20(9):493-498

107. French I, McCulloch D, Boerefijn I, Kooyman N 54.2: Thin plastic electrophoretic displays fabricated by a novel process. In: SID Symposium Digest of Technical Papers, 2005. vol 1. Wiley Online Library, pp 1634-1637

108. Min K, Kim Y, Goyal S, Lee SH, McKenzie M, Park H, Savoy ES, Rammohan AR, Mauro JC, Kim H (2016) Interfacial adhesion behavior of polyimides on silica glass: a molecular dynamics study. Polymer 98:1-10

109. Lee SH, Stewart RJ, Park H, Goyal S, Botu V, Kim H, Min K, Cho E, Rammohan AR, Mauro JC (2017) Effect of nanoscale roughness on adhesion between glassy silica and polyimides: a molecular dynamics study. J Phys Chem C 121(44):24648-24656

110. Goyal S, Park H-H, Lee SH, Savoy E, McKenzie ME, Rammohan AR, Mauro JC, Kim H, Min K, Cho E (2016) Characterizing the fundamental adhesion of polyimide monomers on crystalline and glassy silica surfaces: a molecular dynamics study. J Phys Chem C 120(41):23631-23639

111. Kim D-S, Ahn Y-s, Kim K-J, Yi M-H (2014) Transparent, highly heat-resistant polyimide precursor and photosensitive polyimide composition thereof. US Patent US8703901B2.

112. Huang B, Zhang X, Duan H, Jin H, Huang J (2015) Method for coating polyimide on liquid crystal display panel. US Patent US9144134B2.

113. Dejun B, Liu L, Chen L, Li H, Li J, Shuang D (2019) Composite cover film and flexible display device. US Patent US10566570B2.

114. Liu YQ, Han Y, Lin M, Zhang D, Liu C, Kennedy JT (2019) Polyimide for flexible displays, flexible displays, and methods for making flexible displays. US Patent US20190127529A1.

115. Tianfu G (2019) Fabricating method of oled device and corresponding oled device. US Patent US20190088907A1.

116. Kim G, Kim J, Jeong J, Lee D, Kim M, Lee S, Kim S, Lee H, Han H (2019) High temperature applicable separator by using polyimide aerogel/polyethylene double-layer composite membrane for high-safety lithium ion battery. Int J Electrochem Sci 14:7133-7148

117. Lu Q, Fang J, Yang J, Feng X, Wang J, Nuli Y (2014) A polyimide ion-conductive protection layer to suppress side reactions on Li 4 Ti 5 O 12 electrodes at elevated temperature. RCS Adv 4(20):10280-10283

118. Lee CK, Park YJ (2015) Polyimide-wrapped carbon nanotube electrodes for long cycle $\mathrm{Li}$-air batteries. Chem Commun 51(7):1210-1213
119. Yoon SH, Park YJ (2017) Polyimide-coated carbon electrodes combined with redox mediators for superior $\mathrm{Li}-\mathrm{O} 2$ cells with excellent cycling performance and decreased overpotential. Sci Rep 7:42617

120. Shen F, Wang K, Yin Y, Shi L, Zeng D, Han X (2020) PAN/PI functional double-layer coating for dendrite-free lithium metal anodes. J Mater Chem A 8(13):6183-6189

121. Liu H, Lin X (2019) Polyimide coated lithium titanate particles and use thereof in a lithium ion battery. United States Patent US10381648B2.

122. Li Y, Wang S, Lee P-K, He J, Denis Y (2017) Crack-resistant polyimide coating for high-capacity battery anodes. J Power Sour 366:226-232

123. Lee P-K, Tahmasebi MH, Tan T, Ran S, Boles ST, Denis Y (2019) Polyimide capping layer on improving electrochemical stability of silicon thin-film for Li-ion batteries. Mater Today Energy 12:297-302

124. Salas-Sánchez AÁ, López-Martín ME, Rodríguez-González JA, Ares-Pena FJ (2017) Design of polyimide-coated yagi-uda antennas for monitoring the relative humidity level. IEEE Geosci Remote Sens Lett 14(6):961-963

125. Maeda S, Ono G (2011) Electrode patterning layer comprising polyamic acid or polyimide, and electronic device employing it. US Patent US8044441B2.

126. Maeda S, linuma Y (2017) Polyimide precursor, polyimide, and coating solution for under layer film for image formation. US Patent US9732253B2.

127. Jolley ST, Gibson TL, Williams MK, Parrish CF, Parks SL (2014) Low-melt poly (amic acids) and polyimides and their uses. US Patent US8623253B2.

128. Yoshida K, Yamauchi M, Shiwa M, Hatanaka Y, Imai J, Sugawara J, Shimizu T, Saito H, Furuya Y (2016) Insulating varnish and insulated electrical wire using same. US Patent US9378863B2.

129. Su W-F, Chiang M-H, Hung C-F, Tsai H-J, Chang Y-T, Lin Y-J, Lu T-I (2018) Low-dielectric constant polyimide insulation coating and enameled wire. US Patent US20180053580A1.

130. Minar C, Senn A, Whealon W, Rittenour B (2009) Medical devices with aromatic polyimide coating. US Patent US7627382B2.

131. Liu J, Wang K, Lin L, Liu R, Xie Y, Gao F, Liu X (2016) Synthesis and property of fluorinated polyimides with double bond end groups for UV-cured coating. Prog Org Coat 99:103-109

132. Ngo DD (1997) Photoimageable polyimide coating. US Patent US5599655A.

133. Tsai C-L, Yen H-J, Liou G-S (2016) Highly transparent polyimide hybrids for optoelectronic applications. React Funct Polym 108:2-30

134. Yu YH, Yeh JM, Liou SJ, Chen CL, Liaw DJ, Lu HY (2004) Preparation and properties of polyimide-clay nanocomposite materials for anticorrosion application. J Appl Polym Sci 92(6):3573-3582

135. NASA High-Performance Polyimide Powder Coatings. https ://technology.nasa.gov/patent/KSC-TOPS-23. Accessed 15.04.2020 2020

136. Jolley ST (2017) Low-melt polyamic acid based powder coatings. Google Patents

137. Huang B-S, Lai G-H, Yang T-I, Tsai M-H, Chou Y-C (2020) A novel electroactive imide oligomer and its application in anticorrosion coating. Polymers 12(1):91

138. Huang T-C, Yeh T-C, Huang H-Y, Ji W-F, Chou Y-C, Hung W-I, Yeh J-M, Tsai M-H (2011) Electrochemical studies on anilinepentamer-based electroactive polyimide coating: corrosion protection and electrochromic properties. Electrochim Acta 56(27):10151-10158

139. Weng C-J, Huang J-Y, Huang K-Y, Jhuo Y-S, Tsai M-H, Yeh J-M (2010) Advanced anticorrosive coatings prepared from 
electroactive polyimide-TiO2 hybrid nanocomposite materials. Electrochim Acta 55(28):8430-8438

140. Malav JK, Rathod RC, Umare SS, Patil AP, Ghugal S (2019) Production, measurements and anticorrosion properties of electroactive polyimide/tin oxide nanocomposites. Mater Res Express 6(6):065306

141. Malav JK, Rathod RC, Tandon V, Patil AP (2019) Enhancement of corrosion protection of low nickel austenitic stainless steel by electroactive polyimide-CuO composites coating in chloride environment. Anti Corros Method M 66(6):774-781

142. Chang K-C, Lu H-I, Peng C-W, Lai M-C, Hsu S-C, Hsu M-H, Tsai Y-K, Chang C-H, Hung W-I, Wei Y (2013) Nanocasting technique to prepare lotus-leaf-like superhydrophobic electroactive polyimide as advanced anticorrosive coatings. ACS Appl Mater Interfaces 5(4):1460-1467

143. Bellucci F, Nicodemo L, Monetta T, Kloppers M, Latanision R (1992) A study of corrosion initiation on polyimide coatings. Corros Sci 33(8):1203-1226

144. Feng L, Iroh JO (2014) Corrosion resistance and lifetime of polyimide-b-polyurea novel copolymer coatings. Prog Org Coat 77(3):590-599

145. Feng L, Iroh JO (2018) Polyimide-polyurea copolymer coating with outstanding corrosion inhibition properties. J Appl Polym Sci 135(9):45861

146. Chang K-C, Hsu C, Lu H, Ji W, Chang C, Li W, Chuang T, Yeh J, Liu W, Tsai M (2014) Advanced anticorrosive coatings prepared from electroactive polyimide/graphene nanocomposites with synergistic effects of redox catalytic capability and gas barrier properties. Express Polym Lett 8(4):243-255

147. Lai G, Huang T, Tseng I, Huang B, Yang T, Tsai M (2019) Transparency anticorrosion coatings prepared from alumina-covered graphene oxide/polyimide nanocomposites. Express Polym Lett 13(9):772-784

148. Huangfu M-g, Zhang Y, Zhang X-I, Liu J-g, Liu Y-c, Guo Y-d, Huang Q-y, Zhang X-m (2019) Preparation and thermal evaluation of novel polyimide protective coatings for quartz capillary chromatographic columns operated over $320^{\circ} \mathrm{C}$ for hightemperature gas chromatography analysis. Polymers 11(6):946

149. Baeuml F, Welsch T (2002) Improvement of the long-term stability of polyimide-coated fused-silica capillaries used in capillary electrophoresis and capillary electrochromatography. J Chromatogr A 961(1):35-44

150. McCauley EB (2019) Gas Chromatography Columns with Integrated Ferrules. Google Patents

151. Stolov AA, Slyman BE, Simoff DA, Hokansson AS, Allen RS, Earnhardt JP (2012) Optical fibers with polyimide coatings for medical applications. In: Design and Quality for Biomedical Technologies V. International Society for Optics and Photonics, United States.

152. Jing C, Kendall W, Harrington JA (2016) A simple way to establish a dual-core hollow fiber for laser surgery applications. In: Optical Fibers and Sensors for Medical Diagnostics and Treatment Applications XVI. International Society for Optics and Photonics, United States

153. Lindner E, Cosofret VV, Ufer S, Buck RP, Kusy RP, Ash RB, Nagle HT (1993) Flexible (Kapton-based) microsensor arrays of high stability for cardiovascular applications. J Chem Soc Faraday Trans 89(2):361-367

154. Bernardo P, Drioli E, Golemme G (2009) Membrane gas separation: a review/state of the art. Ind Eng Chem Res 48(10):4638-4663

155. Pendergast MM, Hoek EMV (2011) A review of water treatment membrane nanotechnologies. Energy Environ Sci 4(6):1946-1971
156. Feng $X$, Huang RYM (1997) Liquid separation by membrane pervaporation: a review. Ind Eng Chem Res 36(4):1048-1066

157. Yanagishita H, Kitamoto D, Haraya $K$, Nakane T, Okada T, Matsuda H, Idemoto Y, Koura N (2001) Separation performance of polyimide composite membrane prepared by dip coating process. J Membr Sci 188(2):165-172

158. Cherkashina N, Pavlenko V, Manaev V, Kuprieva O, Kashibadze $\mathrm{N}$, Samoilova E (2020) Multilayer coatings based on polyimide track membranes and nanodispersed lead. Prog Org Coat 138:105432

159. Mehdinia A, Haddad H, Mozaffari S (2016) Polyimide-coated magnetic nanoparticles as a sorbent in the solid-phase extraction of polycyclic aromatic hydrocarbons in seawater samples. J Sep Sci 39(17):3418-3427

160. Spadaccini CM, Mukerjee EV, Letts SA, Maiti A, O'Brien KC (2011) Ultrathin polymer membranes for high throughput $\mathrm{CO} 2$ capture. Energy Procedia 4:731-736

161. Ding Y, Bikson B, Nelson JK (2002) Polyimide membranes derived from poly (amic acid) salt precursor polymers. 2. Composite membrane preparation. Macromolecules. 35(3):912-916

162. Langsam M (2018) Polyimides for gas separation. Polyimides. CRC Press, Florida, pp 697-742

163. Xiao Y, Low BT, Hosseini SS, Chung TS, Paul DR (2009) The strategies of molecular architecture and modification of polyimidebased membranes for $\mathrm{CO} 2$ removal from natural gas: a review. Prog Polym Sci 34(6):561-580

164. Liu Y, Liu Z, Liu G, Qiu W, Bhuwania N, Chinn D, Koros WJ (2020) Surprising plasticization benefits in natural gas upgrading using polyimide membranes. J Membr Sci 593:117430

165. Castro-Muñoz R, Galiano F, de la Iglesia Ó, Fíla V, Téllez C, Coronas J, Figoli A (2019) Graphene oxide-Filled polyimide membranes in pervaporative separation of azeotropic methanolMTBE mixtures. Sep Purif Technol 224:265-272

166. Li P, Ma J, Xu H, Xue X, Liu Y (2016) Highly stable copper wire/ alumina/polyimide composite films for stretchable and transparent heaters. J Mater Chem C 4(16):3581-3591

167. Tseng I-H, Hsieh T-T, Lin C-H, Tsai M-H, Ma D-L, Ko C-J (2018) Phosphinated polyimide hybrid films with reduced melt-flow and enhanced adhesion for flexible copper clad laminates. Prog Org Coat 124:92-98

168. Dai J, Sullivan DM, Bruening ML (2000) Ultrathin, layered polyamide and polyimide coatings on aluminum. Ind Eng Chem Res 39(10):3528-3535

169. Huttunen-Saarivirta E, Yudin V, Myagkova L, Svetlichnyi V (2011) Corrosion protection of galvanized steel by polyimide coatings: EIS and SEM investigations. Prog Org Coat 72(3):269-278

170. Liu Y, Suo X, Wang Z, Gong Y, Wang X, Li H (2017) Developing polyimide-copper antifouling coatings with capsule structures for sustainable release of copper. Mater Des 130:285-293

171. Wang X, Liu Y, Gong Y, Suo X, Li H (2017) Liquid flame spray fabrication of polyimide-copper coatings for antifouling applications. Mater Lett 190:217-220

172. Görlach B, Holweger W (2005) Future polyimide coatings used in high loaded bearings. Ind Lubr Tribol 57(5):197-201

173. Wan H, Jia Y, Ye Y, Xu H, Cui H, Chen L, Zhou H, Chen J (2017) Tribological behavior of polyimide/epoxy resin-polytetrafluoroethylene bonded solid lubricant coatings filled with in situsynthesized silver nanoparticles. Prog Org Coat 106:111-118

174. Çakir M, Akin E (2019) Wear, thermal, and physical properties of fluorine-containing polyimide/silica hybrid nanocomposite coatings. J Appl Polym Sci 136(16):47399

175. Çakir M, Akin E, Artir R (2019) Coating properties of $1 \mathrm{H}, 1 \mathrm{H}$-perfluorooctylamine-terminated polyimides based on hexafluoroisopropylidene diphthalic anhydride and 1,4,5,8 naphthalenetetracarboxylic dianhydride. J Coat Technol Res 16(3):699-710 
176. Roy A, Mu L, Shi Y (2020) Tribological properties of polyimide coating filled with carbon nanotube at elevated temperatures. Polym Compos 41(7):2652-2661

177. Roy A, Mu L, Shi Y (2020) Tribological properties of polyimidegraphene composite coatings at elevated temperatures. Prog Org Coat 142:105602

178. Li Y, Zhang Q, Ruan H, Li F, Xu X, Huang X, Lu S (2019) Improving the tribological and mechanical properties of polyimide composites by incorporating functionalized graphene. High Perform Polym 32(1):21-29

179. Chung DDL, Chung D (2012) Carbon fiber composites. Butterworth-Heinemann, Massachusetts

180. Naganuma T, Naito K, Yang J-M, Kyono J, Sasakura D, Kagawa $Y$ (2009) The effect of a compliant polyimide nanocoating on the tensile properties of a high strength PAN-based carbon fiber. Compos Sci Technol 69(7-8):1319-1322

181. Naito K (2013) The effect of high-temperature vapor deposition polymerization of polyimide coating on tensile properties of polyacrylonitrile-and pitch-based carbon fibers. J Mater Sci 48(17):6056-6064

182. Naganuma T, Naito K, Yang J-M (2011) High-temperature vapor deposition polymerization polyimide coating for elimination of surface nano-flaws in high-strength carbon fiber. Carbon 49(12):3881-3890

183. He S, Zhang S, Lu C, Wu G, Yang Y, An F, Guo J, Li H (2011) Polyimide nano-coating on carbon fibers by electrophoretic deposition. Colloids Surf Physicochem Eng Aspects 381(1-3):118-122

184. Yuan H-j, Lu C-x, Zhang S-c, Wu G-p (2015) Preparation and characterization of a polyimide coating on the surface of carbon fibers. New Carbon Mater 30(2):115-121

185. He S, Lu C, Zhang S (2011) Facile and efficient route to polyimide-TiO2 nanocomposite coating onto carbon fiber. ACS Appl Mater Interfaces 3(12):4744-4750

186. He S, Zhang S, Lu C (2011) Coating carbon fiber using polyimide-silica nanocomposite by electrophoretic deposition. Colloids Surf Physicochem Eng Aspects 387(1-3):86-91

187. Karataş S, Kayaman-Apohan N, Demirer H, Güngör A (2007) Polyimide-silica hybrid coatings: morphological, mechanical, and thermal investigations. Polym Adv Technol 18(6):490-496

188. Serbezeanu D, Popa AM, Stelzig T, Sava I, Rossi RM, Fortunato G (2015) Preparation and characterization of thermally stable polyimide membranes by electrospinning for protective clothing applications. Text Res J 85(17):1763-1775

189. Butnaru I, Serbezeanu D, Bruma M, Sava I, Gaan S, Fortunato G (2015) Physical and thermal properties of poly (ethylene terephthalate) fabric coated with electrospun polyimide fibers. High Perform Polym 27(5):616-624

190. Lee J, Kim SS, Kang D, Roh C, Kang C (2019) Physicochemical characterization of polyimide (PI)/p-aramid: new functional and safe materials with improved heat resistance by a simple coating of polyimide on the surface of $p$-aramid. Prog Org Coat 127:117-123

191. Malik N, Shrivastava S (2019) Synthesis and characterization of fire resistance polymeric coating solution for carbon-blended aluminized (E-glass-based) and non-aluminized fabric. J Text Inst 110(12):1-6

192. Liu J, Li Y, Li M, Arumugam S, Beeby SP (2019) Processing of printed dye sensitized solar cells on woven textiles. IEEE J Photovolt 9(4):1020-1024

193. Industries F (2020) Optical Fibers. https://www.fiberguide.com/ product/optical-fibers/. Accessed 14.04.2020 2020

194. Fibercore (2020) Polyimide Coated SM Fiber. https://www. fibercore.com/product/polyimide-coated-sm-fiber. Accessed 14.04.2020 2020
195. Thorlabs (2020) Polyimide-Coated Single Mode Fiber. https ://www.thorlabs.com/newgrouppage9.cfm?objectgroup_ $\mathrm{id}=13401$. Accessed 14.04.2020 2020

196. Molex (2016) Polymicro Technologies ${ }^{\mathrm{TM}}$ Synthetic fused silica with polyimide coating capillary. http://www.literature.molex .com/SQLImages/kelmscott/Molex/PDF_Images/987651-3171. PDF. Accessed 15.04.2020 2020

197. Joe Z, Rick T (2009) High Temperature Polyimide Coating at $400{ }^{\circ} \mathrm{C}$ Molex. https://www.molex.com/mx_upload/super family/polymicro/pdfs/High_Temperature_Polyimide_Coati ng_at_400oC_Oct_2009.pdf. Accessed 15.04.2020 2020

198. Zeus-Incorporation Polyimide Coating. https://www.zeusi nc.com/wp-content/uploads/2019/07/Polyimide-MaterialV1R1.pdf. Accessed 15.04.2020 2020

199. Hilgenberg-GMBH (2020) Polyimide coated filling needles. https://www.hilgenberg-gmbh.de/en/product-novelties/polyi mide-coated-filling-needles/. Accessed 14.04.2020 2020

200. Aculon (2020) Polyimide Hydrophobic \& Oleophobic Coatings. https://www.aculon.com/repellency-treatments/hydrophobi c-coatings/hydrophobic-oleophobic-polyimide/. Accessed 14.04.2020 2020

201. -Inc. C-T-D (2013) CTD-201 Polyimide Coating. https://www. ctd-materials.com/wordpress/wp-content/uploads/2014/05/ CTD201-Polyimide-Coating-December-2013.pdf. Accessed 15.04.2020 2020

202. UBE-Industries Polyimide varnish "UPIA ${ }^{\oplus " . ~ h t t p: / / w w w . u p i l e ~}$ x.jp/en/varnish.html. Accessed 10.09.2019 2019

203. Pyre-M.L. ${ }^{\circledR}$ Polyimide Varnish for Heat-Resistant Insulation Coating. https://www.istcorp.jp/en/industrial_material/pyre$\mathrm{ml} /$. Accessed 09.10.2019 2019

204. HEF Groupe, TEGLISS ${ }^{\text {TM }}$ Varnish. https://www.hef.fr/en/Varni sh.html. Accessed 09.10.2019 2019

205. Toray-Industries-Incorporation (2020) High-heat Resistant Polyimide Coatings Semicofine. https://www.toray.co. jp/english/electronic/products/pro_b002.html. Accessed 14.04.2020 2020

206. Toray-Industries-Incorporation (2020) High-heat Resistant Polyimide Coatings Photoneece. https://www.toray.co.jp/english/ electronic/products/pro_b001.html. Accessed 14.04.2020 2020

207. Precision-Coating ${ }^{\mathrm{TM}}$ Polyimide. https://www.precisioncoatin g.com/engineered-coatings/polyimide/. Accessed 15.04.2020 15.04 .2020

208. $3 \mathrm{M}^{\mathrm{TM}}$ Polyimide Tape. https://www.3m.com/3M/en_US/compa ny-us/all-3m-products/ /All-3M-Products/Adhesives-Tapes/ Industrial-Adhesives-and-Tapes/Specialty-Tapes/PolyimideTape/? $\mathrm{N}=5002385+8710676+8710815+8710978+87110$ $17+8731789+3294857497 \&$ \&t $=r 3$. Accessed 09.10.2019 2019

209. Profile IT (2020) Polyimide Coating / Polyimide Film. http:// www.itp.my/index.php/products/polyimide-coating-polyi mide-film. Accessed 14.04.2020 2020

210. UBE-Industries (2020) UPILEX ${ }^{\circledR}$ Super-heat resistant polyimide film. https://www.ube.com/upilex/en/upilex.html. Accessed 14.04.2020 2020

211. Dunmore (2020) Polyimide Film. https://www.dunmore.com/ technical/polyimide-film.html. Accessed 14.04.2020 2020

212. American-Durafilm Durafilm ${ }^{\oplus}$ Polyimide coating. https://ameri candurafilm.com/polyimide-coating/. Accessed 15.04.2020 2020

213. Berrux A, Muller P-j, Perillon J-L (2014) Cooking article including an external polyimide-based coating. US Patent US8851319B2.

214. Shen L, Rong Z, Mian D (2019) Coatings, methods and coated articles. US Patent US20190194491A1.

215. Fadeev AG, Chang T, Bookbinder DC, Pal S, Saha CK, DeMartino SE, Timmons CL, Peanasky JS (2017) Glass articles with lowfriction coatings. US Patent US9918898B2. 
216. Liu Y, Xu X, Suo X, Gong Y, Li H (2018) Suspension flame spray construction of polyimide-copper layers for marine antifouling applications. J Therm Spray Technol 27(1):98-105

217. Lee J, Kim SS, Kang D, Roh C, Kang C (2019) Physicochemical characterization of polyimide (PI) / p-aramid: new functional and safe materials with improved heat resistance by a simple coating of polyimide on the surface of $p$-aramid. Prog Org Coat 127:117-123

218. Pichaimani P, Krishnan S, Song J-K, Muthukaruppan A (2018) Bio-silicon reinforced siloxane core polyimide green nanocomposite with multifunctional behavior. High Perform Polym 30(5):549-560

219. Zhi X, Bi H, Liu J, Gao Y, Zhang Y, Zhou Y, Zhang Y, Wu X, Zhang $X$ (2019) Synthesis and characterization of soluble ester-containing polyimide alignment layers with high voltage holding ratio features and potential applications in TFT-LCDs. Express Polym Lett 13(10):923-936

220. Constantin C-P, Damaceanu M-D, Bruma M, Begunov RS (2019) Ortho-Catenation and trifluoromethyl graphting as driving forces in electro-optical properties modulation of ethanol soluble triphenylamine-based polyimides. Dyes Pigm 163:126-137

221. St Clair AK, Slemp WS (1985) Evaluation of colorless polyimide film for thermal control coating applications. Paper presented at the NASA Technical Memorandum, Hampton

222. Zhang Q, Tsai C-Y, Li L-J, Liaw D-J (2019) Colorless-to-colorful switching electrochromic polyimides with very high contrast ratio. Nat Commun 10(1):1239

223. Kim TH, Kim M, Manda R, Lim YJ, Cho KJ, Hee H, Kang J-W, Lee G-D, Lee SH (2019) Flexible Liquid Crystal Displays Using Liquid Crystal-polymer Composite Film and Colorless Polyimide Substrate. Curr Opt Photonics 3(1):66-71

224. Huang $X$, Zhang F, Liu Y, Leng J (2019) Flexible and colorless shape memory polyimide films with high visible light transmittance and high transition temperature. Smart Mater Struct 28(5):055031

225. Moon J-Y, Youn D-Y, Kim C, Lee J-H, Luo Z, Kim I-D (2018) Metal nanotrough embedded colorless polyimide films: transparent conducting electrodes with exceptional flexibility and high conductivity. Nanoscale 10(17):7927-7932
226. Daito A, Sekiguchi S (2019) Polyimide resin film and method for producing polyimide resin film. US Patent US20190185631A1.

227. Pavlenko Vl, Cherkashina NI, Yastrebinsky RN (2019) Synthesis and radiation shielding properties of polyimide $/ \mathrm{Bi} 2 \mathrm{O} 3 \mathrm{com}$ posites. Heliyon 5(5):e01703

228. Zhou Y, Wu S, Liu F (2019) High-performance polyimide nanocomposites with polydopamine-coated copper nanoparticles and nanowires for electronic applications. Mater Lett 237:19-21

229. Rasekh M, Rafiee Z (2019) Preparation and properties of polyimide-based nanocomposites containing functionalized Fe3O4 nanoparticles. High Perform Polym 32(4):418-428

230. Wu X, Zhang Y, Du P, Jin Z, Zhao H, Wang L (2019) Synthesis, characterization and properties of graphene-reinforced polyimide coatings. New J Chem 43(15):5697-5705

231. Castro-Muñoz R, Galiano F, de la Iglesia Ó, Fíla V, Téllez C, Coronas J, Figoli A (2019) Graphene oxide: filled polyimide membranes in pervaporative separation of azeotropic methanolMTBE mixtures. Sep Purif Technol 224:265-272

232. Zhang F, Feng Y, Qin M, Gao L, Li Z, Zhao F, Zhang Z, Lv F, Feng W (2019) Stress controllability in thermal and electrical conductivity of 3D elastic graphene-crosslinked carbon nanotube sponge/polyimide nanocomposite. Adv Funct Mater 29(25):1901383

233. Min C, Liu D, Shen C, Zhang Q, Song H, Li S, Shen X, Zhu M, Zhang K (2018) Unique synergistic effects of graphene oxide and carbon nanotube hybrids on the tribological properties of polyimide nanocomposites. Tribol Int 117:217-224

234. Li J, Yuan X, Liu S, He Z, Zhou Z, Li A (2017) A low-cost and high-performance sulfonated polyimide proton-conductive membrane for vanadium redox flow/static batteries. ACS Appl Mater Interfaces 9(38):32643-32651

Publisher's Note Springer Nature remains neutral with regard to jurisdictional claims in published maps and institutional affiliations. 